NBER WORKING PAPER SERIES

HOUSEHOLD FINANCE OVER THE LIFE-CYCLE: WHAT DOES EDUCATION CONTRIBUTE?

\author{
Russell Cooper \\ Guozhong Zhu \\ Working Paper 20684 \\ http://www.nber.org/papers/w20684
NATIONAL BUREAU OF ECONOMIC RESEARCH
1050 Massachusetts Avenue
Cambridge, MA 02138
November 2014

We are grateful to the NSF for financial support. Participants at seminars at Pennsylvania State University, SUFE and SED 2014 provided helpful questions and comments. Thanks to David Lander and Qi Wu for detailed comments and suggestions. The views expressed herein are those of the authors and do not necessarily reflect the views of the National Bureau of Economic Research.

NBER working papers are circulated for discussion and comment purposes. They have not been peerreviewed or been subject to the review by the NBER Board of Directors that accompanies official NBER publications.

(C) 2014 by Russell Cooper and Guozhong Zhu. All rights reserved. Short sections of text, not to exceed two paragraphs, may be quoted without explicit permission provided that full credit, including $\odot$ notice, is given to the source. 
Household Finance over the Life-Cycle: What does Education Contribute?

Russell Cooper and Guozhong Zhu

NBER Working Paper No. 20684

November 2014

JEL No. E21,G11

\begin{abstract}
$\underline{\text { ABSTRACT }}$
This paper studies household financial choices: why are these decisions dependent on the education level of the household? A life-cycle model is constructed to understand a rich set of facts about decisions of households with different levels of educational attainment regarding stock market participation, the stock share in wealth, the stock adjustment rate and the wealth-income ratio. Model parameters, including preferences, the cost of stock market participation and portfolio adjustment costs, are estimated to match the financial decisions of different education groups. Based on the estimated model, education affects household finance mainly through increased average income. The estimation also finds evidence that higher educational attainment is associated with a lower stock market entry cost and a larger discount factor. Education specific differences in income risks, medical expenses, mortality risks and the life-cycle pattern of income explain relatively little of the observed differences in household financial choices.
\end{abstract}

\author{
Russell Cooper \\ Department of Economics \\ The Pennsylvania State University \\ 611 Kern \\ State College, PA 16802 \\ and NBER \\ russellcoop@gmail.com \\ Guozhong Zhu \\ Guanghua School of Management \\ Peking University \\ Beijing, China \\ gzhu@gsm.pku.edu.cn
}




\title{
Household Finance over the Life-Cycle: What does Education Contribute?*
}

\author{
Russell Cooper ${ }^{\dagger}$ and Guozhong Zhu
}

November 10, 2014

\begin{abstract}
This paper studies household financial choices: why are these decisions dependent on the education level of the household? A life-cycle model is constructed to understand a rich set of facts about decisions of households with different levels of educational attainment regarding stock market participation, the stock share in wealth, the stock adjustment rate and the wealth-income ratio. Model parameters, including preferences, the cost of stock market participation and portfolio adjustment costs, are estimated to match the financial decisions of different education groups. Based on the estimated model, education affects household finance mainly through increased average income. The estimation also finds evidence that higher educational attainment is associated with a lower stock market entry cost and a larger discount factor. Education specific differences in income risks, medical expenses, mortality risks and the life-cycle pattern of income explain relatively little of the observed differences in household financial choices.
\end{abstract}

\section{Motivation}

Empirical studies have consistently revealed the importance of education for household financial decisions. Asset market participation decision, stock adjustment rate, savings rate and portfolio choice are frequently linked to educational attainment.

For example, Campbell (2006) presents evidence on the determinants of public equity market participation and portfolio composition. His regressions indicate that both income and education have a significant influence on household financial choices. Using changes in compulsory schooling laws as instruments, Cole, Paulson, and Shastry (2014) shows empirically that education causes higher investment income and equity ownership.

But what is the underlying impact of education on financial decisions? Are different household decisions a consequence of education specific observables such as income processes, health risks and mortality rates, and/or

\footnotetext{
*We are grateful to the NSF for financial support. Participants at seminars at Pennsylvania State University, SUFE and SED 2014 provided helpful questions and comments. Thanks to David Lander and Qi Wu for detailed comments and suggestions.

$\dagger$ Department of Economics, the Pennsylvania State University and NBER, russellcoop@gmail.com

${ }_{\ddagger}$ Department of Applied Economics, Guanghua School of Management, Peking University, gzhu@gsm.pku.edu.cn
} 
unobservable types of heterogeneity that are correlated with educational attainment, such as risk aversion and cognitive abilities? Addressing these questions is the purpose of this paper. ${ }^{1}$

The analysis is built upon empirical evidence linking education and household financial choices including: asset market participation, the share of risky assets in household portfolios, the frequency of portfolio adjustment and wealth-income ratios. While a few studies have focused on one or more of these components of household financial decisions, one contribution of the paper is to understand these choices jointly. ${ }^{2}$ This is important not just as means of generating a more complete picture of these choices but in allowing us to identify the sources of these differences. For example, a household considering asset market participation will recognize the subsequent costs of portfolio adjustment which is evidenced by the low stock adjustment rate. The factors, such as attitudes towards risk, that determine the share of assets in a household portfolio will also influence wealth accumulation and the stock market participation decision of the household. Another example is that, with fixed portfolio adjustment cost, higher wealth levels may lead to a higher stock share as wealthy households bear a lower cost (per unit) of adjustment. This stock share decision interacts with the participation decision, creating identification problems when participation is not modeled explicitly.

Our approach to determining the dependence of financial choices on education starts with the specification and estimation of a life-cycle model of household financial choices. Regression analysis, as in Campbell (2006), reveals how household finance depends on education and income in a static way. Our framework allows us to study the dynamic effects of education specific traits. For example, the model shows the important role of permanent income over the life-cycle, rather than realized income at a point in time. The life-cycle framework, rather than the infinitely lived agent model, is needed to examine the affects of post-retirement income and stochastic medical expenses on pre-retirement financial decisions.

Most of the existing quantitative studies on household portfolio choice is based on calibrated parameters, including important papers such as Cocco, Gomes, and Maenhout (2005), Gomes and Michaelides (2005), Gomes and Michaelides (2008) and Wachter and Yogo (2010). ${ }^{3}$ By contrast, estimation is an integral part of our analysis. Based on the estimated model parameters, we are able to quantify the channels of influence between education and household financial decisions. Further, we would not be able to analyze the link between education and the parameters of household preferences and adjustment costs without estimating the parameters. The estimation uses a simulated method of moments approach, where the moments reflect the key household financial decisions by education group. These moments are selected to identify key parameters.

More specifically, the analysis puts households into four groups according to the educational attainment of house-heads. ${ }^{4}$ From the Survey of Consumer Finance (SCF), the average stock market participation rate and the financial wealth to income ratio increase sharply with education. Stock share also increases with education status,

\footnotetext{
${ }^{1}$ Cole, Paulson, and Shastry (2014) offers some informal discussions about why education leads to different financial decisions. We formally answer the above questions based on an estimated structural model.

${ }^{2}$ For example, Hubbard, Skinner, and Zeldes (1995) study why more educated households save more. Achury, Hubar, and Koulovatianos (2012) and Wachter and Yogo (2010) study the relation between education (or wealth) and stock share in wealth.

${ }^{3}$ Structural estimation is employed in Alan (2006) and Bonaparte, Cooper, and Zhu (2012). But the former studies participation only and the latter stock share only, neither looks at education differences.

${ }^{4}$ To be clear, the model does not explain education. Rather it looks at the household financial choices given education.
} 
but not as sharply. From the Panel Study of Income Dynamics (PSID), stock (portfolio) adjustment rates are higher for more educated households.

Parameter estimates come from using the structural model to match the life-cycle profiles of stock market participation rates, stock share in wealth, stock adjustment rates and wealth-income ratios of the four education groups. ${ }^{5}$ The coefficients from regressing these household financial variables on, inter alia, age and age-squared and education dummies generates moments that are very informative about costs and risk preferences. By matching these moments, we estimate costs associated with stock market participation and adjustment along with preference parameters. In addition, by allowing heterogeneity in preferences and costs across education groups, the estimation results enable us to study the roles played by risk aversion, patience and other unobservables.

The recent literature provides insights that costs associated with stock market participation, eg. VissingJorgensen (2002b), Alan (2006), Gomes and Michaelides (2005), and costs of stock transactions, eg. Bonaparte, Cooper, and Zhu (2012), are important. We consider both types of costs, assuming both are fixed rather than proportional to income or wealth. In the presence of these costs, our model is able to match the increase of participation, adjustment rate, portfolio share and wealth-income ratio with education. Further, our structural estimation allows us the test to what extent these costs are education specific.

In the absence of costs, predictions based on common representations of risk preferences tend to contradict the data. For example, standard household portfolio models typically predict that every household should participate in the stock market, and that the stock share in total financial wealth should be high, e.g. Heaton and Lucas (1997). As another example, constant absolute risk aversion preferences predict that a household's optimal investment in risky assets is roughly a fixed amount independent of total wealth, which implies that the more educated should have a lower share of stocks in financial wealth.

As pointed out by Campbell (2006), a fundamental issue that confronts the household finance literature is how to specify the household utility function. We carry out the estimation using three specifications: constant absolute risk aversion (CARA), constant relative risk aversion (CRRA) and recursive utility (EZW) taken from Epstein and Zin (1989) and Weil (1990). Our estimation results indicate that recursive utility brings the model and data moments closer together than do the CARA and CRRA representations. Apart from understanding the link between education and financial choices, the finding in support of the recursive utility specification in an estimated model is of independent interest. This result based on estimating the competing models, complements existing simulation based exercises that have documented the contribution of this specification of utility.

A critical input into the household optimization problem is the education specific stochastic processes for income, medical expenses and mortality. Education impacts both the permanent and transitory components of labor income. Based on the PSID, more educated households have higher levels of deterministic income, and smaller transitory income shocks before retirement. According to data from the Health and Retirement Study (HRS), after retirement, the more educated have higher out-of-pocket medical expenses relative to their income, and are subject to lower mortality risks.

\footnotetext{
${ }^{5}$ The estimation of parameters from life-cycle profiles is a main feature distinguishing this paper from our earlier study, Cooper and Zhu (2013).
} 
In answer to the central question of our paper, the main observable factor that links household financial decisions to education is the dependence of the mean level of income on education. ${ }^{6}$ Other factors, such as income volatility and differences in both medical expenses and mortality risk do not play a large role in explaining the variation of household financial decisions across education groups.

We also allow preferences, the stock market entry cost and the portfolio adjustment cost to differ across education groups. Point estimates show that, compared to less educated households, more educated households (i) face lower stock market entry cost, and (ii) discount the future less. Other differences in parameters are not significant and have little power in explaining differences across education groups.

\section{Data Facts}

We present two types of data facts. The first are the processes characterizing exogenous labor income, out-of-pocket medical expenses during retirement and mortality risks faced by households. These processes, taken as exogenous, influence the extent to which households accumulate precautionary savings balances and how they structure their portfolios. $^{7}$

The second set of facts concerns household financial choices: asset market participation, stock share in portfolios, the frequency of stock adjustment and wealth-income ratio. These dimensions of household financial choices reflect both the aforementioned processes that households face as well as the costs of participation and adjustment. The life-cycle patterns of these choices become the moments to match in the estimation of household preference parameters and adjustment costs.

Consistent with the motivation of the paper, the exogenous processes for income, mortality and medical expenses as well as the moments summarizing household choices are presented by education group. A key point of the paper is to go beyond these education specific observable facts to understand why education matters.

\subsection{Heterogeneity of Exogenous Processes}

Households are broken into four groups by (highest) educational attainment of the household head. Specifically they have years of schooling less than 12 years, equal to 12 years, over 12 but less than or equal to 16 and over 16 years respectively. Household income is defined as the sum of labor income and transfers. The data are from the Panel Study of Income Dynamics (1989-2007). The Appendix provides detailed information on sample selection criteria and the decomposition method.

\footnotetext{
${ }^{6}$ Wachter and Yogo (2010) relate the rise of stock share with educational attainment to a luxury goods assumption, underlying which is the higher income of the more educated. Similarly, Achury, Hubar, and Koulovatianos (2012) link income level to stock share through subsistence consumption.

${ }^{7}$ Endogenous income as a result of flexible labor supply will lead to more risk taking of working households, which is shown in Bodie, Merton, and Samuelson (1992) and Gomes, Kotlikoff, and Viceira (2008). Regarding medical expenses, DeNardi, French, and Jones (2010) compare the results on wealth accumulation from models with exogenous and endogenous medical expenses and find little difference.
} 
The process of log income at the household level is composed of deterministic and stochastic components:

$$
y_{i, t}=\bar{y}_{i, t}+\tilde{y}_{i, t} .
$$

Here $i$ indexes the household and $t$ is the time period.

As is common to empirical models that use panel data sets, age, time and cohort effects are impossible to generally separate. This is an issue for the income processes characterized in this section as well as the moments summarizing household financial decisions presented later. ${ }^{8}$

A common practice in the literature is to separate age effects and time effects in the data. We follow this in the baseline specification. Accordingly, the empirical model of deterministic income includes age $a_{i}$ and time $t$ as well as other covariates, $X_{i}$ :

$$
\bar{y}_{i, t}=\gamma_{0}+\gamma_{1} a_{i}+\gamma_{2} t+\gamma_{3} X_{i}
$$

In practice, we use age and year dummies for $a_{i}$ and $t$ to allow for non-linear age and time effects. Since, on average, income is growing over time, removing time effects from age effects leads to a stationary age profile of income. Consistent with this treatment, the time effects are separated from age effects for each of the household finance variables in the baseline model.

As an alternative specification, the cohort effects, rather than then time effects, are included in the covariates to remove their influence. That is, the deterministic income depends on age $a_{i}$ and the cohort of the individual, $c_{i}$, and other covariates:

$$
\bar{y}_{i, t}=\gamma_{0}+\gamma_{1} a_{i}+\gamma_{2} c_{i}+\gamma_{3} X_{i} .
$$

With this specification, the role of time and age are not separated. Thus any deterministic trend in income is embodied in age effects, leading to a steeper age profile of income. For robustness, we also study this alternative specification of income, and the associated financial choice moments that allow for cohort effects as well.

Figure 1 presents the profiles of deterministic income of the four education groups, for the two treatments of cohort and time effects. ${ }^{9}$ The left-side controls for year effects, as in (2), and the right-side controls for cohort effects, as in (3).

The focus of this research is on differences in financial behavior by education group. A starting point for this appears in the mean of the paths which clearly illustrate gains to education. These differences in mean income by education group will account for a large amount of the differences in household financial decisions by education group.

All the profiles have a hump-shape, though the magnitude depends on the treatment of time and cohort effects. For the high education group, deterministic income rises much more rapidly with age when cohort effects are controlled for compared to the alternative. This reflects a rising return to education during the sample period, which magnifies the age effects in (3).

\footnotetext{
${ }^{8}$ Ameriks and Zeldes (2004) provide a thorough discussion of these issues in the context of household finance moments.

${ }^{9} \mathrm{~A}$ very similar figure appears in Cocco, Gomes, and Maenhout (2005) though for a different sample period.
} 

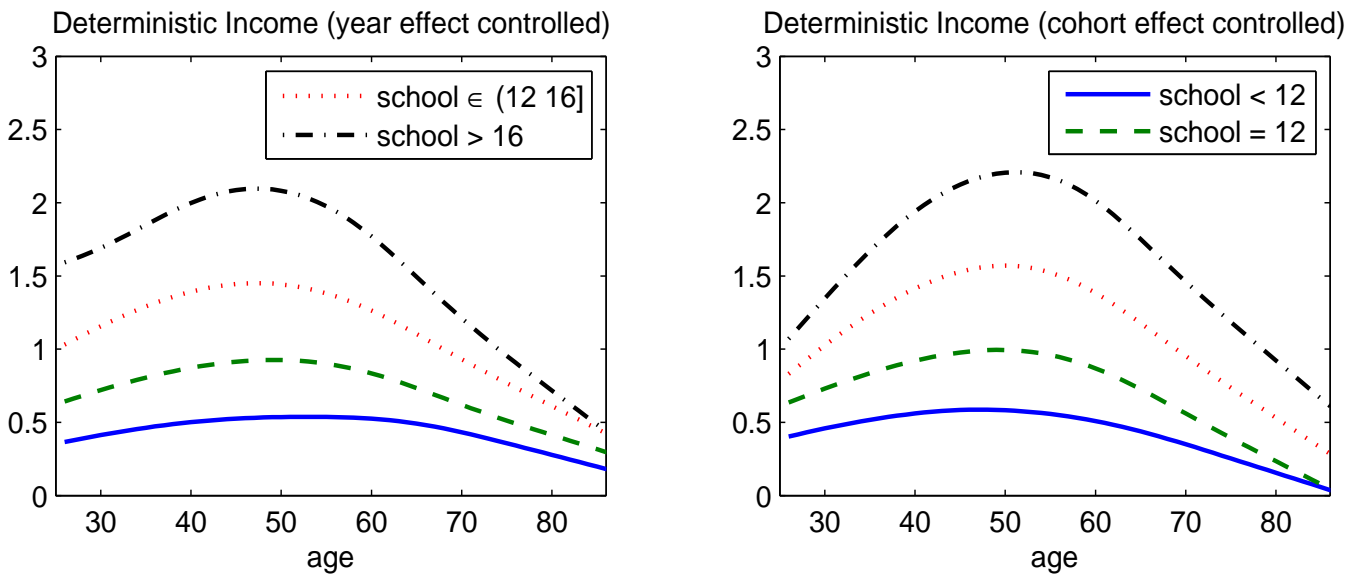

Figure 1: Pre-retirement Deterministic Income

This figure shows the average profiles of deterministic income by educational attainment. Income profiles are normalized so that the average income of the pooled households is one.

By assumption, post-retirement income is deterministic. Income falls with age after retirement as shown in Figure 1.

The stochastic component of pre-retirement income, $\tilde{y}_{i, t}$, is decomposed into transitory and persistent shocks.

$$
\begin{gathered}
\tilde{y}_{i, t}=z_{i, t}+\epsilon_{i, t} \\
z_{i, t}=\rho z_{i, t-1}+\eta_{i, t}
\end{gathered}
$$

where $\epsilon_{i, t}$ and $\eta_{i, t}$ are independent zero-mean random shocks, with variance $\sigma_{\epsilon}^{2}$ and $\sigma_{\eta}^{2}$ respectively. The shock $\eta_{i, t}$ is persistent, with a parameter of $\rho$. The accumulation of persistent shocks is represented by $z_{i, t}$. The Appendix provides additional details on this decomposition and the estimation of these stochastic income processes.

Table 1: Stochastic Processes for Income

\begin{tabular}{cccc}
\hline \hline & \multicolumn{3}{c}{ Income } \\
\hline years of school & $\sigma_{\epsilon}^{2}$ & $\sigma_{\eta}^{2}$ & $\rho$ \\
$<12$ & 0.107 & 0.017 & 0.963 \\
& $(0.017)$ & $(0.004)$ & $(0.007)$ \\
12 & 0.071 & 0.016 & 0.952 \\
& $(0.007)$ & $(0.002)$ & $(0.004)$ \\
$\epsilon(12,16]$ & 0.067 & 0.018 & 0.960 \\
& $(0.007)$ & $(0.004)$ & $(0.006)$ \\
$>16$ & 0.020 & 0.037 & 0.935 \\
& $(0.008)$ & $(0.007)$ & $(0.009)$ \\
\hline \hline
\end{tabular}

This table reports the variances and persistence parameters of income shocks estimated from PSID (1989-2007) for four education groups. Standard errors are presented in parentheses.

The stochastic properties of income for different groups are presented in Table 1. The rows denote the years of 

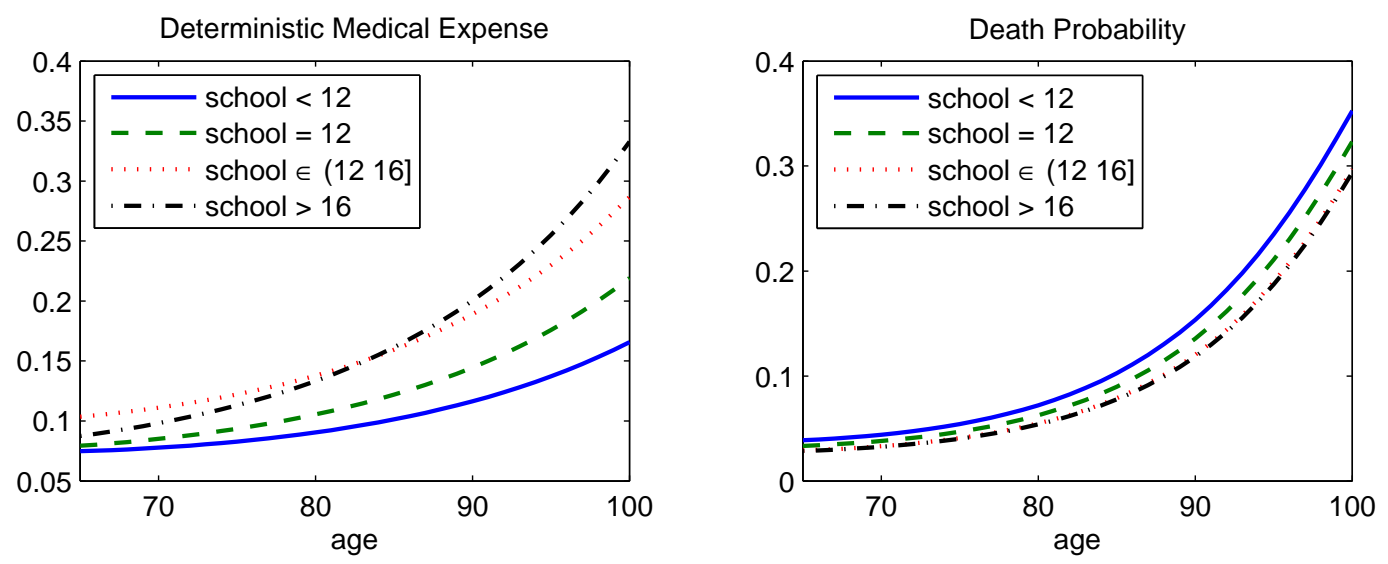

Figure 2: Post-Retirement Medical Expenses and Death Probability

The left panel shows the average profiles of post-retirement out-of-pocket medical expense relative to post-retirement income by education group. The right panel is the estimated death probability conditional on survival.

schooling of the household head. Households with more educated heads are exposed to smaller transitory income shocks. The persistence and size of persistent income shocks are about the same across education groups, except that the most educated group appears to have less persistent but larger shocks. ${ }^{10}$

While their income is deterministic, retired households are subject to medical expense shocks. The estimation of out-of-pocket medical expenses is based on data from French and Jones (2004). That paper shows that the logarithm of stochastic component of out-of-pocket medical expenses can be well represented by an $A R(1)$ process plus a transitory shock. We assume the stochastic process of medical expenses to be the same across education groups, and take the estimates directly from French and Jones (2004). We estimate the ratio of out-of-pocket medical expenses to post-retirement income for each education group. Details about data sources, definitions and the stochastic process for medical expenses are given in the Appendix.

Deterministic out-of-pocket medical expenses relative to post-retirement income is plotted in the left panel of Figure 2. Medical expenses relative to income increases sharply with age. What's more important for this paper is the increase of expenses with educational attainment, although the increase emerges after age 85 for the two most educated groups.

The right panel of Figure 2 shows death probability as a function of age by education group. Consistent with the literature, see for example Lleras-Muney (2005) and Starr-McCluer (1996), less educated individuals are faced with higher mortality risks.

In the estimation of the model, these income, medical expense and mortality processes are taken as exogenous inputs. Moreover, the variance of income innovations varies by education class. As noted above, we restrict the

\footnotetext{
${ }^{10}$ Some other papers in the literature also find the less educated are exposed to larger transitory income shocks. Examples include Guvenen (2009) (Table 1) and Hubbard, Skinner, and Zeldes (1994) (Appendix A.4). The t-statistics reported in Hubbard, Skinner, and Zeldes (1994) imply that these parameters are imprecisely estimated. One the other hand, Carroll and Samwick (1997) (Table 1) offer very precise estimates, but find a non-monotone relation between educational attainment and size of income shocks.
} 
variability of medical expenses post-retirement to be the same across education groups.

\section{$2.2 \quad$ Patterns of Household Finance}

The life-cycle profiles of asset market participation, the share of stocks in financial assets, the portfolio adjustment rate and the wealth-income ratio are used to motivate our analysis. These profiles are later used as moments for structural estimation of preferences and costs associated with stock market participation and portfolio adjustment.

A household is a participant in asset markets if it either directly or indirectly owns stocks according to our sample from the SCF. The share of stocks in a household's total financial wealth is the ratio of stock holdings to the sum of stock and bond holdings. ${ }^{11}$ Adjustment refers to the actual purchase or sale of stocks by the household as well as the reinvestment of dividends. This is measured bi-annually. This adjustment rate includes changes in IRA-holdings. Automatic reinvestments are not considered as adjustments. The wealth-income ratio is presented both with and without the inclusion of net housing equity in wealth. The Appendix provides additional detail on data sources and definitions.

To obtain the patterns of stock market participation, stock share and adjustment rate, we regress each variable on a constant, age, age-squared, education dummies, and year dummies. For wealth-income ratio, the interaction of education dummies with age and age-squared are also included in the regression. We exclude these interactions in the regression of participation, stock share and adjustment rate, because the shape of profiles are similar across education groups. On the other hand, the life-cycle profile of wealth-income ratio is much steeper for more educated households, thus the age-education interaction is necessary. As with the income profiles, in the robustness check we control for cohort effects instead of year effects for these household finance variables. These regression coefficients, reported in Table 2, will be used as the data moments in the simulated method of moments estimation.

Figure 3 reports the life-cycle patterns of household finance by education group. Participation rates and wealthincome ratios increase sharply with educational attainment. The stock share and the adjustment rate increase as well, though not as much. The rise of median wealth-income ratio with educational attainment is consistent with the finding that richer households save more, as in Dynan, Skinner, and Zeldes (2004). Using Swedish data, Calvet, Campbell, and Sodini (2007) and Calvet, Campbell, and Sodini (2009) show that more educated households participate in the equity market more, have riskier portfolio and adjust their stock account more.

Over the life-cycle, the participation rate, adjustment rate and share (without housing) are hump-shaped. The wealth-income ratio, both with and without housing, is increasing with age. This partly reflects the drop in income post-retirement but also the slow deaccumulation of wealth. As in DeNardi, French, and Jones (2010), a challenge for the estimation will be to replicate the increase in the wealth-income ratio as a function of age.

These patterns provide guidance on the model we construct. The incentives for asset accumulation reflected in the wealth to income ratio will come from income risks, low post-retirement income, post-retirement medical expense risks and a bequest motive. The discount factor, risk aversion, and the value of bequests will determine the response of financial choices to income patterns.

\footnotetext{
${ }^{11}$ This measure is adjusted as explained below when housing is included in the data and the model. Here we do not consider the demand for money. See Aoki, Michaelides, and Nikolov (2012) for recent work integrating money demand into portfolio choice.
} 

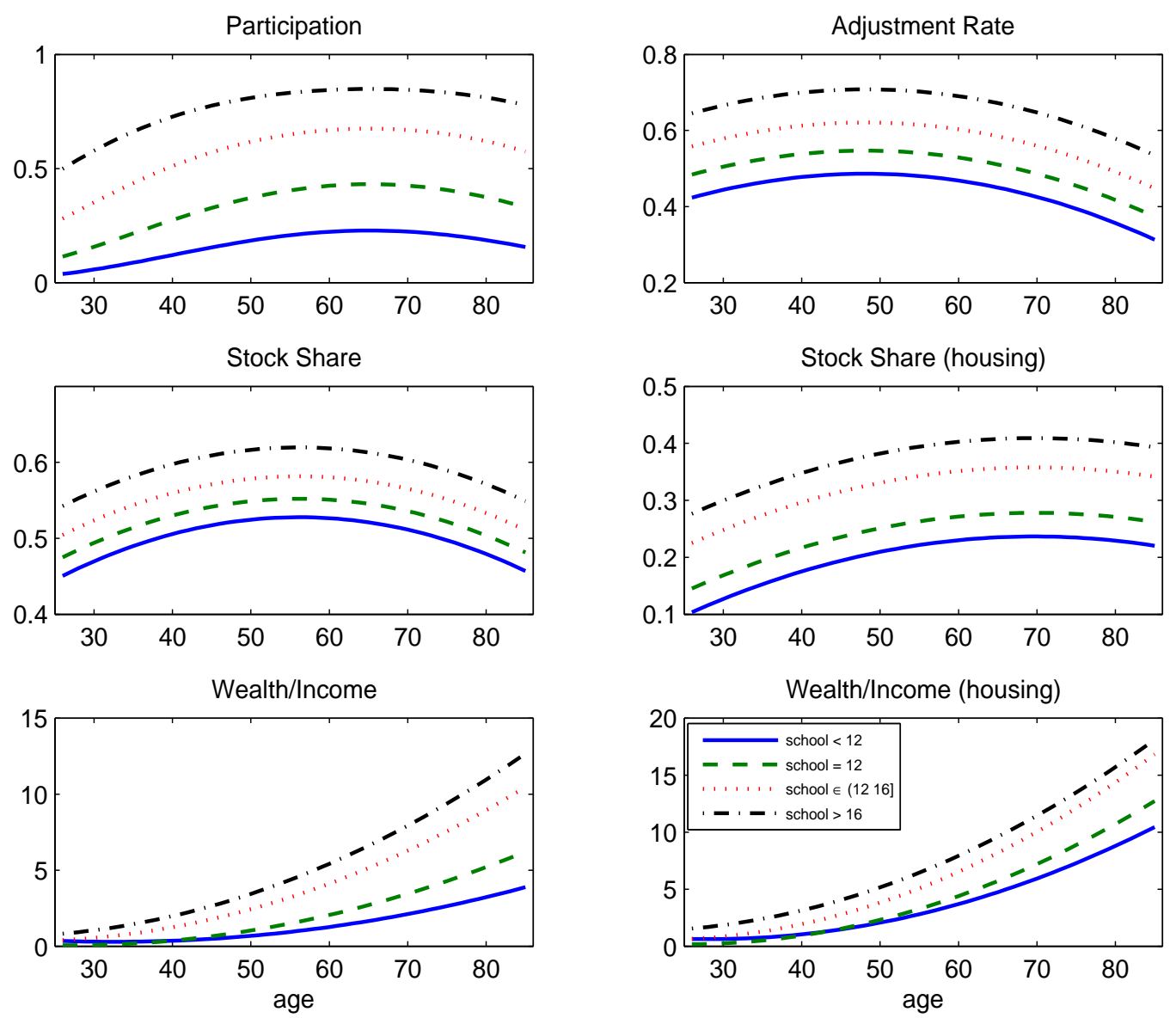

Figure 3: Profiles of Household Financial Decisions

These profiles show the age dependence of household financial decisions. With the exception of the wealth-income equation, these come from a linear regression model with a constant, age, age-squared, time dummies and education dummies as independent variables. For the wealth-income regressions, the independent variables were a constant, age, age-squared, time dummies and education dummies interacted with age and age-squared. For the figures labelled 'housing', home equity is included in the measurement of wealth.

The costs of asset market participation as well as the costs of portfolio adjustment are relevant for understanding the frequency of adjustment, the participation decisions and the portfolio shares. A unique feature of our study is the presence of both of these costs. Having moments on participation as well as adjustment rates will allow us to identify them. As with the savings decision, household preferences also influence adjustment and participation choices.

\section{Model}

To infer parameters from these moments requires an optimization model at the household level. Both the participation and adjustment decisions are discrete while the portfolio share is a continuous choice variable. We embed these discrete and continuous decisions into a life-cycle framework. 


\subsection{Dynamic Optimization Problem}

A household makes consumption, saving and financial choices during its working and retirement period. The retirement age, $T^{r}$, is exogenous in our analysis. In periods $t=1,2,3, \ldots, T^{r}$ the household is working and earns a stochastic income, characterized in Table 1 and Figure 1. Confronting the riskiness of income while working is a main motive for household finance choices. The household is faced with a death probability which is a function of age, education and permanent income. The death probability equals one at age $T+1$ for each education group, so that the maximum life span is $T$. In the quantitative analysis, $T^{r}=65$ and $T=95$.

At $t=T^{r}$ the household's income is deterministic, following the pattern in Figure 1. During retirement, the household faces stochastic medical expenses. As described above, following DeNardi, French, and Jones (2010), these medical expenses are treated as variations in household disposable income and thus are a source of risk during retirement.

The state of a household of age $t$ in education group $e$ is its current labor income $y_{t}^{e}$, its medical expenses $m_{t}^{e}$, its current holdings of stocks, denoted $A^{s}$, and bonds, denoted $A^{b}$, and the return on assets $R$. Income and medical expenses are superscripted by educational attainment, $e$. These exogenous difference across education groups will lead to endogenous difference in saving and financial choices. Let $\Omega=\left(y_{t}^{e}, m_{t}^{e}, R, A\right)$ represent the current state, with $A=\left(A^{b}, A^{s}\right)$ being a vector of endogenous state variables. Notice that the distribution of $R$ is time (age) invariant and independent of educational attainment.

The dynamic optimization problem of the household is formulated with time separable preferences. This presentation is consistent with familiar CARA and CRRA preference specifications and allows us to highlight the participation and adjustment decisions of households. Section 3.2 enriches the model by considering a recursive utility formulation, as in Epstein and Zin (1989) and Weil (1990).

A household currently not participating in the stock market has the choice in period (at age) $t$ to remain outside of that market or to pay an entry cost for the right to trade stocks. That discrete choice is represented as:

$$
w_{e, t}(\Omega)=\max \left\{w_{e, t}^{n}(\Omega), w_{e, t}^{p}(\Omega)\right\}
$$

for all $\Omega$. Here $w_{e, t}(\Omega)$ is the maximum of the values of participating, $w_{e, t}^{p}(\Omega)$, and not participating, $w_{e, t}^{n}(\Omega)$. The value functions are subscripted by educational attainment and age because of the finite-horizon nature of the optimization problem.

If the household chooses to remain outside of asset markets, the household can engage in consumption smoothing through its bond account and re-optimize in the following period. The value of that problem is given by:

$$
w_{e, t}^{n}(\Omega)=\max _{A^{b^{\prime}} \geq \underline{A}^{b}} u(c)+\beta E_{y_{t+1}^{e}, m_{t+1}^{e}} \mid y_{t}^{e}, m_{t}^{e}\left\{\nu_{t+1}^{e} w_{e, t+1}\left(\Omega^{\prime}\right)+\left(1-\nu_{t+1}^{e}\right) B\left(R^{b} A^{b^{\prime}}\right)\right\}
$$

for all $\Omega$. Here $\beta$ is the discount factor, $v_{t+1}^{e}$ is the survival probability, as indicated in the right panel of Figure 2 . 
$B\left(b^{\prime}\right)$ is the value of leaving a bequest of size $b^{\prime}$ and is explained in detail below. Consumption is given by

$$
c=y_{t}^{e}+T R_{t}-m_{t}^{e}+R^{b} A^{b}-A^{b \prime} .
$$

Here $T R_{t}$ is the transfer from the government from various social insurance programs. Following Hubbard, Skinner, and Zeldes (1995) and DeNardi, French, and Jones (2010), we assume the following functional form for this transfer

$$
T R_{t}=\max \left\{0, \underline{c}-\left(y_{t}^{e}+R^{b} A^{b}-m_{t}^{e}\right)\right\}
$$

where $\underline{c}$ is the consumption floor, the minimum level of consumption guaranteed by the government. In order to be eligible for the transfer, a household's means of living net of medical expenses, $y_{t}^{e}+R^{b} A^{b}-m_{t}^{e}$, must be less than the floor. Therefore the transfer function captures asset-based, means-tested social programs such as Medicaid, food stamps and Temporary Assistance for Needy Families. This support program has implications for precautionary savings, particularly by low wealth households.

In this problem, there is a lower bound on bond holdings, $\underline{A}^{b}$. The household is not allowed to own stocks as it is a non-participant in the stock market. Hence in (6), $A^{s}=A^{s \prime}=0$ is imposed.

If a household chooses to participate in the stock market, then it incurs an entry cost of $\Gamma$ and becomes a participant with future value of $v_{e, t+1}(\Omega)$. This cost is assumed to be paid one time and is not a flow participation cost. This switch in status happens instantly and the household is in a position to make portfolio adjustment decisions. The value of participating is given by:

$$
w_{e, t}^{p}(\Omega)=\max _{A^{b^{\prime}} \geq \underline{A}^{b}, A^{s^{\prime}} \geq 0} u(c)+\beta E_{y_{t+1}^{e}, m_{t+1}^{e}, R^{s^{\prime}} \mid y_{t}^{e}, m_{t}^{e}, R^{s}}\left\{\nu_{t+1}^{e} v_{e, t+1}\left(\Omega^{\prime}\right)+\left(1-\nu_{t+1}^{e}\right) B\left(R^{b} A^{b^{\prime}}+R^{s^{\prime}} A^{s^{\prime}}\right)\right\}
$$

s.t.

$$
\begin{gathered}
c=y_{t}^{e}+T R_{t}-m_{t}^{e}+R^{b} A^{b}-A^{b \prime}-A^{s \prime}-\Gamma \\
T R_{t}=\max \left\{0, \underline{c}-\left(y_{t}^{e}+R^{b} A^{b}-m_{t}^{e}\right)\right\} .
\end{gathered}
$$

Here the bequest value is a function of total wealth, including the liquidated value of stocks. The household chooses a bequest portfolio without knowing the stock return that will determine the full value of the inheritance.

A participant in asset markets has a discrete choice between adjusting, not adjusting its stock account or exiting asset markets. This choice is represented as:

$$
v_{e, t}(\Omega)=\max \left\{v_{e, t}^{a}(\Omega), v_{e, t}^{n}(\Omega), v_{e, t}^{x}(\Omega)\right\}
$$

for all $\Omega$. 
If the household adjusts, it is able to adjust both its stock and bond accounts. The household solves:

$$
v_{e, t}^{a}(\Omega)=\max _{A^{b^{\prime}} \geq \underline{A}^{b}, A^{s^{\prime}} \geq 0} u(c)+\beta E_{y_{t+1}^{e}, m_{t+1}^{e}, R^{s^{\prime}} \mid y_{t}^{e}, m_{t}^{e}, R^{s}}\left\{\nu_{t+1}^{e} v_{e, t+1}\left(\Omega^{\prime}\right)+\left(1-\nu_{t+1}^{e}\right) B\left(R^{b} A^{b^{\prime}}+R^{s^{\prime}} A^{s^{\prime}}\right)\right\}
$$

s.t.

$$
\begin{gathered}
c=y_{t}^{e}+T R_{t}-m_{t}^{e}+\sum_{i=b, s} R^{i} A^{i}-\sum_{i=b, s} A^{i^{\prime}}-F \\
T R_{t}=\max \left\{0, \underline{c}-\left(y_{t}^{e}+\sum_{i=b, s} R^{i} A^{i}-m_{t}^{e}\right)\right\} .
\end{gathered}
$$

In this problem, there is again a lower bound to bond holdings which we assume is the same as that for nonparticipants. The household is not allowed to sell stocks short. The transfer function in (13) is the same as (8) for non-participants, except that the means of living now includes wealth from stock holdings.

The $F$ in budget constraint (12) is the cost of adjusting stock account. It is assumed to be independent of educational attainment, age and income. It is possible to include an additional adjustment cost proportional to income as in Bonaparte, Cooper, and Zhu (2012), as well as flow costs of asset market participation, as discussed in Vissing-Jorgensen (2002b). For matching the moments that are the focus of this study, this fixed adjustment cost along with the participation cost are sufficient. ${ }^{12}$ As we shall see, the cost of adjustment induces exit from stock participation. In addition, these costs are important for the forward-looking household's choice to participate in asset markets.

The adjustment cost should be interpreted as a comprehensive measure of commission, time cost of adjustment and cost of information search. Much of these costs are not directly observable, but are closely related to the observed infrequent adjustment of stock account. By matching the adjustment rates of different education groups, both pre- and post-retirement, we obtain quite precise estimates of the fixed cost.

A household that participates in asset markets but chooses not to adjust its stock portfolio is able to freely adjust its bond portfolio. The value of no-adjustment is given by:

$$
v_{e, t}^{n}(\Omega)=\max _{A^{b \prime} \geq \underline{A}^{b}} u(c)+\beta E_{y_{t+1}^{e}, m_{t+1}^{e}, R^{s^{\prime}} \mid y_{t}^{e}, m_{t}^{e}, R^{s}}\left\{\nu_{t+1}^{e} v_{e, t+1}\left(\Omega^{\prime}\right)+\left(1-\nu_{t+1}^{e}\right) B\left(R^{b} A^{b^{\prime}}+R^{s^{\prime}} A^{s^{\prime}}\right)\right\}
$$

s.t

$$
\begin{gathered}
c=y_{t}^{e}+T R_{t}-m_{t}^{e}+R^{b} A^{b}-A^{b \prime} \\
A^{s \prime}=R^{s} A^{s} \\
T R_{t}=\max \left\{0, \underline{c}-\left(y_{t}^{e}+\sum_{i=b, s} R^{i} A^{i}-m_{t}^{e}\right)\right\}
\end{gathered}
$$

where $A^{s \prime}=R^{s} A^{s}$ since the return on stocks is (costlessly) reinvested into the stock account.

Finally, a household may choose to exit the stock market. This choice is particularly pertinent for agents late in life. The value of exit is given by:

\footnotetext{
${ }^{12}$ See Gomes and Michaelides (2005) and Alan (2006), among others, for models with participation costs alone.
} 


$$
\begin{aligned}
& v_{e, t}^{x}(\Omega)=\max _{A^{b \prime} \geq \underline{A}^{b}} u(c)+\beta E_{y_{t+1}^{e}, m_{t+1}^{e} \mid y_{t}^{e}, m_{t}^{e}}\left\{\nu_{t+1}^{e} w_{e, t+1}\left(\Omega^{\prime}\right)+\left(1-\nu_{t+1}^{e}\right) B\left(R^{b} A^{b^{\prime}}\right)\right\} \\
& \text { s.t. } \\
& c=y_{t}^{e}+T R_{t}-m_{t}^{e}+\sum_{i=b, s} R^{i} A^{i}-A^{b \prime} \\
& T R_{t}=\max \left\{0, \underline{c}-\left(y_{t}^{e}+\sum_{i=b, s} R^{i} A^{i}-m_{t}^{e}\right)\right\} .
\end{aligned}
$$

This dynamic discrete choice problem allows us to capture the pertinent choices of market participation and portfolio adjustment. One of the interesting tensions, explored in Bonaparte, Cooper, and Zhu (2012), in the household's problem is how to respond to income shocks. For small fluctuations in income, adjustment in the bond account will be adequate for consumption smoothing. For large fluctuations in income, the household will need to adjust its stock and bond holdings jointly, thus incurring that adjustment cost. The riskiness of income influences the portfolio choice: all else the same, a riskier income process implies a more liquid (a lower stock to bond ratio) portfolio.

There is also a richness in the participation decision. By participating in stock markets, household can take advantage of a higher average return. But that higher return comes at two costs: stocks are riskier and more expensive to trade.

Differences between pre- and post-retirement come into play in a couple of ways. First, entry into asset markets is a type of investment and thus the gains to participation will depend on the horizon of the household, along with the discount factor. Second, the income process changes over the life-cycle.

Finally, there is the exit decision from asset markets. Since retirement income is lower on average than that during working life, participation ought to fall during retirement. Further, due to the presence of large medical expense shocks during retirement (modeled as large income shocks), a household may be induced to liquidate stock holdings in low income states and then exit from asset markets.

\subsection{Preferences}

Three types of preferences are considered. Estimating preference parameters beyond the traditional CRRA specification is one of the contributions of this paper.

The first is the commonly used CRRA preferences (power utility), with

$$
u(c)=\frac{1}{1-\gamma} c^{1-\gamma}
$$

The second one is CARA preferences (exponential utility), with

$$
u(c)=-e^{-\gamma c} .
$$

As is well understood from Merton (1971), for example, these two preference structures impose certain properties 
on portfolio shares when markets are complete. Under CRRA the portfolio share of the risky asset is constant. Under CARA, the amount invested in the risky asset is constant so that its share is lower in larger portfolios. Neither of restrictions imposed by these two extremes fit the data well, though both are used for convenience in theoretical and some empirical exercises. Further, we have incomplete markets: households bear some risk due to idiosyncratic shocks.

Finally, we go beyond these familiar representations and consider a recursive utility model where the current value depends on current consumption and the expected future value. The EZW representation of preferences, taken from Epstein and Zin (1989) and Weil (1990), is given by

$$
V_{e, t}=\left\{(1-\beta) c^{1-1 / \theta}+\beta\left[\nu_{t+1}^{e}\left(E_{t} V_{e, t+1}^{1-\gamma}\right)^{\frac{1}{1-\gamma}}+\left(1-\nu_{t+1}^{e}\right)\left(E_{t} B_{t+1}^{1-\gamma}\right)^{\frac{1}{1-\gamma}}\right]^{1-1 / \theta}\right\}^{\frac{1}{1-1 / \theta}},
$$

where $V_{e, t}$ is a state-dependent value of the optimization problem, and the bequest value $B_{t+1}$ is a function of wealth left behind upon the household's death. Here the bequest value is subscripted by $t$ to remind the readers that it depends on the realization of stock return in period $t+1$. Different education groups have the same functional form of $B_{t+1}$.

This representation allows more flexibility by distinguishing risk aversion $(\gamma)$ from the elasticity of intertemporal substitution $(\theta)$. Bhamra and Uppal (2006) discuss the portfolio implications of this preference structure. Among other things, they point out that in the face of stochastic returns, the portfolio choice depends jointly on the elasticity of substitution and the degree of risk aversion, i.e. the parameters $(\theta, \gamma)$. As in Weil (1990), noninterest income is deterministic in their analysis. Relatively few quantitative studies of household portfolio choice, Gomes and Michaelides (2005) being a prime exception, use this specification of preferences in a fully stochastic environment. ${ }^{13}$

\subsection{Bequest Value}

Denote wealth, and hence the bequest of an agent, at death by $Z$. The utility flow from a bequest, in the case of CRRA preferences, is:

$$
B(Z)=L \frac{(\phi+Z)^{1-\gamma}}{1-\gamma}
$$

For the CARA preferences, the specification in (23) changes accordingly. For the EZW preferences, the bequest function is:

$$
B(Z)=L(\phi+Z) .
$$

\footnotetext{
${ }^{13}$ Gomes and Michaelides (2005) provide simulation results for a variety of parameterizations, illustrating the sensitivity of participation and portfolio shares to risk aversion and the intertemporal elasticity of substitution. Cocco, Gomes, and Maenhout (2005) consider EZW preferences in their simulations and study the sensitivity of portfolio shares to the EIS. In contrast to our paper, there is no estimation in either paper.
} 
The curvature parameter $\gamma$ appears in (22) rather than (23).

For each of the bequest functions, the parameters $L$ and $\phi$ determine the utility flow from a bequest. $L$ measures the strength of the bequest motive, and $\phi$ measures the degree of luxuriousness of a bequest. ${ }^{14}$ With $\phi>0$, a bequest is a luxury good and the utility of a bequest becomes non-homothetic. In section 7.1, we will show that $\phi$ plays an important role in generating differences in the wealth-income ratio by education.

With EZW preferences the effect of variations in $L$ on the strength of the bequest motive depends on the sign of $\frac{\theta-1}{\theta}$. This point is clear when one looks at the first-order condition for the optimization problem in the last period: the marginal value of a bequest is multiplied by $\beta L^{\frac{\theta-1}{\theta}}$.

\subsection{Education Choice}

The human capital decision is made prior to the portfolio choice. Suppose that the net cost of education is given by the random variable $\psi$ which is distributed across the population. Differences in the cost of education could reflect heterogeneity in ability, in the socioeconomic status of parents, in school quality, etc. Given a draw of $\psi$, households will optimally choose the amount of education. Having made this decision, education only matters for household financial choices through the processes for income, mortality and medical expenses. It is precisely these effects of education choice that we capture through the mapping of education specific processes to household financial choices in our initial estimation.

There could be heterogeneity across households that is not directly observable but underlies their education choices. Some of these differences would have no effect on household saving and portfolio choice. For example, households may differ in the disutility of time spent studying relative to leisure, as in Keane and Wolpin (2001).

Other factors, such as the discount factor, could explain the education choice. Further, education itself could influence parameters such as participation costs and adjustment costs, which is studied in the literature of financial literacy. ${ }^{15}$ Moreover, factors such as cognitive ability which help to determine the education choice, may also matter for household financial decisions. These possibilities are explored when parameters are allowed to vary by education type. ${ }^{16}$

\section{Quantitative Analysis}

The quantitative analysis of the model revolves around estimating the parameters of the household optimization problem as well as adjustment costs to match key moments from the data. To do so, the various preference representations in section 3.2 are studied.

The initial set of estimates focuses on the effects of education specific processes that are directly observable in the data. The goal is to understand the relative importance of these observable factors. Accordingly, we initially assume that all households have identical preferences and stock market cost parameters in section 5 .

\footnotetext{
${ }^{14}$ This structure also appears in, inter alia, Gomes and Michaelides (2005), DeNardi, French, and Jones (2010) and Cagetti (2003).

${ }^{15}$ See, for example, Lusardi (2008).

${ }^{16}$ Bringing together the education choice, say as in Keane and Wolpin (2001), along with the complex financial decisions modeled in this paper would be of interest and could place further restrictions on parameters.
} 
Section 6 broadens the analysis to allow parameter differences as well. These results are then used to determine to what extent unobservable heterogeneity accounts for differences in household finance relative to the differences in observable exogenous processes.

\subsection{Approach}

The estimation of the processes for income, stock returns, out-of-pocket medical expenses and mortality are independent of the structural model. Preference parameters and costs related to stock market are estimated by simulated method of moments. The estimation of the set of structural parameters, $\Theta \equiv(\beta, \gamma, \Gamma, F, L, \phi, \underline{c}, \theta)$, is based on the the following problem:

$$
£=\min _{\Theta}\left(M^{s}(\Theta)-M^{d}\right) W\left(M^{s}(\Theta)-M^{d}\right)^{\prime}
$$

where $W$ is a weighting matrix, discussed in Section 9.4 of the Appendix.

In the set of parameters, $\beta$ is the discount factor, $\gamma$ is the curvature (risk aversion) of the utility function and $\theta$ is the EIS for the EZW specification. There are two parameters for the bequest function, $(L, \phi)$. There are two types of costs: $\Gamma$ the cost to participate in the stock market and $F$, the fixed trading cost. Finally, $\underline{c}$ is the consumption floor both pre- and post-retirement. Agents are not able to borrow so that $\underline{A}^{b}=0$. This is consistent with the argument in Hubbard, Skinner, and Zeldes (1995) that the presence of a consumption floor limits borrowing.

Table 2 presents the moments for our analysis. These are essentially the coefficients used to generate the age profiles for household financial decisions shown in Figure 3. These regression coefficients are used as moments in the estimation of the structural parameters.

By this choice of moments, we have elected to summarize the life-cycle profile through a regression on age and age-squared. This contrasts with an approach that substitutes age specific dummies for the quadratic specification. The quadratic approximation captures the basic life-cycle patterns in a parsimonious way. ${ }^{17}$

The simulated moments, $M^{s}(\Theta)$, are calculated from the simulated data set created by solving the household optimization problem specified in equations (5) to (23) given the parameter vector $\Theta$ and a representation of utility. The moments from the simulated data are calculated in the same way as the moments from the actual data.

The initial distribution of assets is important for the moments generated by the solution of the model. For example, a household may never participate in the stock market if it is not a participant initially, but may stay in the stock market until the end of life if it is in the market initially. This is because participation status itself has value due to the entry cost. Hence the mean level of participation, a key moment, will depend on initial conditions.

We estimate the initial distribution of households on the product space of stock and bond holdings from the SCF. ${ }^{18}$ Using this initial condition, we simulate the paths of consumption, stockholding and bond holding for a large number of households to create a simulated panel given a vector of parameters. The moments in (25) are calculated from this panel and the objective function is evaluated for a given value of $\Theta$.

\footnotetext{
${ }^{17}$ The age specific dummies would focus attention on certain aspects of the life-cycle, such as retirement, that are not central to our analysis.

${ }^{18}$ Section 9.3 in the Appendix provides some statistics from this initial distribution.
} 
Table 2: Regression Coefficients From the Data

\begin{tabular}{|c|c|c|c|c|c|c|c|c|c|}
\hline & & & year effe & ct controll & & & & & \\
\hline \multirow{3}{*}{ part. } & const. & age & age $^{2}$ & $e d u_{2}$ & $e d u_{3}$ & $e d u_{4}$ & & & \\
\hline & -0.680 & 0.029 & -0.00023 & 0.182 & 0.412 & 0.603 & & & \\
\hline & $(-18.16)$ & $(25.79)$ & $(-20.81)$ & $(16.05)$ & $(38.79)$ & $(51.84)$ & & & \\
\hline \multirow[t]{2}{*}{ share } & 0.260 & $9.5 \mathrm{E}-03$ & -0.00009 & 0.024 & 0.054 & 0.092 & & & \\
\hline & $(6.197)$ & $(7.722)$ & $(-7.462)$ & $(1.558)$ & $(3.69)$ & (6.194) & & & \\
\hline \multirow[t]{3}{*}{ adj. } & 0.189 & 0.012 & -0.00013 & 0.061 & 0.135 & 0.222 & & & \\
\hline & $(1.897)$ & $(3.749)$ & $(-4.226)$ & $(1.795)$ & $(4.325)$ & $(6.844)$ & & & \\
\hline & const. & age & $\operatorname{age}^{2}$ & $e d u_{2} \times$ age & $e d u_{3} \times$ age & $e d u_{4} \times$ age & $e d u_{2} \times \operatorname{age}^{2}$ & $e d u_{3} \times \operatorname{age}^{2}$ & $e d u_{4} \times \operatorname{age}^{2}$ \\
\hline \multirow[t]{4}{*}{$\mathrm{W} / \mathrm{I}$} & 1.393 & -0.086 & $1.3 \mathrm{E}-03$ & -0.012 & -0.015 & -0.004 & 0.00051 & 0.00114 & 0.00130 \\
\hline & $(2.94)$ & $(-5.287)$ & $(7.495)$ & $(-1.136)$ & $(-1.498)$ & $(-0.317)$ & $(3.104)$ & $(7.299)$ & $(7.211)$ \\
\hline & & & cohort ef & ect control & ed & & & & \\
\hline & const. & age & age $^{2}$ & $e d u_{2}$ & $e d u_{3}$ & $e d u_{4}$ & & & \\
\hline \multirow[t]{2}{*}{ part } & -0.783 & 0.029 & -0.00020 & 0.181 & 0.412 & 0.602 & & & \\
\hline & $(-4.621)$ & $(13.92)$ & $(-9.714)$ & $(15.89)$ & $(38.69)$ & $(51.60)$ & & & \\
\hline \multirow[t]{2}{*}{ share } & 0.357 & -0.003 & 0.00008 & 0.023 & 0.052 & 0.088 & & & \\
\hline & $(1.786)$ & $(-1.236)$ & $(3.880)$ & $(1.465)$ & $(3.534)$ & $(5.881)$ & & & \\
\hline \multirow[t]{3}{*}{$\operatorname{adj}$} & 0.582 & 0.000 & -0.00004 & 0.046 & 0.118 & 0.200 & & & \\
\hline & $(0.466)$ & $(-0.014)$ & $(-0.305)$ & $(1.332)$ & $(3.744)$ & $(6.061)$ & & & \\
\hline & const. & age & $\operatorname{age}^{2}$ & $e d u_{2} \times$ age & $e d u_{3} \times$ age & $e d u_{4} \times$ age & $e d u_{2} \times \operatorname{age}^{2}$ & $e d u_{3} \times$ age $^{2}$ & $e d u_{4} \times \operatorname{age}^{2}$ \\
\hline \multirow[t]{2}{*}{$\mathrm{W} / \mathrm{I}$} & 1.706 & -0.072 & 0.00102 & -0.010 & -0.012 & 0.003 & 0.00047 & 0.00106 & 0.00119 \\
\hline & $(0.786)$ & $(-2.554)$ & $(3.620)$ & $(-0.901)$ & $(-1.101)$ & $(0.215)$ & $(2.788)$ & $(6.712)$ & $(6.468)$ \\
\hline
\end{tabular}

These are the coefficient estimates obtained by regressing the four elements of household financial choices. With the exception of the wealth-income equation, these come from a linear regression model with a constant, age, age-squared, time dummies and education dummies as independent variables. For the wealth-income regressions, the independent variables were a constant, age, age-squared, time dummies, and education dummies interacted with age and age-squared. Here and in the tables that follow $e d u_{i}$ denotes education group $i=1,2,3,4$ ordered by years of schooling. Point estimates of the constant term are adjusted by year/cohort effect coefficients, so that the levels match the averages over different waves of surveys. Standard errors are adjusted correspondingly.

\section{Homogenous Parameters}

This section estimates the structural parameters under the assumption of no differences in parameters across education groups. The next section allows heterogeneous preferences and cost parameters.

\subsection{Estimation Results}

The estimation results are reported in Tables 3 and Figure 4. The results for the three leading preference specifications are shown, CRRA, CARA and EZW. The last two rows, labeled EZW(I) and EZW(c), are explained in Section 5.2 where we discuss robustness of the estimation results.

\subsubsection{Parameter Estimates}

Table 3 shows the parameter estimates as well as the fit. Under each parameter estimate is the standard error. As indicated by the last column of the table, the fit of the EZW specification is considerably better than either of the alternative preference representations. ${ }^{19}$ Hereafter we take the EZW specification with homogeneous parameters as

\footnotetext{
${ }^{19}$ Of course the EZW model nests CRRA. The point is to see that the restriction of the CRRA case is rejected.
} 
the baseline. The baseline model will be compared with various extensions such as housing in wealth, heterogeneous preferences and the model with cohort effects controlled.

Regarding the parameter estimates for the EZW model, the discount factor is estimated at 0.862 , below conventional estimates, and the estimated risk aversion is 4.409. For the EZW specification, $\theta$ controls the elasticity of intertemporal substitution and is 0.601 . The estimated $\theta$ is much larger than $\frac{1}{\gamma}$ so the time separable CRRA model is rejected.

The identification of high EIS (relative to $\frac{1}{\gamma}$ ) largely comes from the post-retirement profile of wealth accumulation and stock market participation. A large fraction of wealth accumulation before retirement is the buffer stock against income shocks. This precautionary motive becomes much weaker after retirement, because income shocks disappear and medical expense shocks are largely transitory. Therefore households need to run down precautionary wealth. If the EIS is too low, households reduce wealth too slowly, leading to wealth-income ratio profiles that are too steep. This also implies that participation rates should remain high until very old age. In summary, a reasonably high EIS is chosen to match the participation and wealth-income ratio profiles in the data.

For comparison, the baseline calibration of Gomes and Michaelides (2005) assumes: $\beta=0.96, \gamma=5, \theta=0.2$, $\Gamma=0.025$. Binsbergen, Fernandez-Villaverde, Koijen, and Ramirez (2012) estimate a DSGE model with EZW preferences based on the term structure of interest rate. The estimated $\gamma$ ranges from 41-85 and the EIS ranges from 1.30-2.01, implying even larger risk aversion and inter-temporal substitution. Based on consumption Euler equation, Vissing-Jorgensen (2002a) estimates the EIS to be around 0.3-1.0. Cagetti (2003) estimates a $\beta$ around 0.98 for college educated while his estimated discount factor is between 0.85 and 0.90 for high school education and below.

The participation cost, $\Gamma$, and adjustment costs, $F$, are each statistically and economically significant. ${ }^{20}$ The values reported are fractions of the average pre-retirement income of all households. Thus the entry cost is about $1.0 \%$ of average income. The adjustment cost is larger, about $2.0 \%$, of average income. The average household income in terms of 2010 US dollar in our PSID sample is about $\$ 68,400$. Therefore the entry and adjustment costs are about $\$ 684$ and $\$ 1,368$ respectively. In comparison, Bonaparte, Cooper, and Zhu (2012) estimate fixed trading costs of about $\$ 900$ though in that model there are no participation costs and everybody participates. While large relative to income, these costs are, of course, much more modest relative to financial wealth.

The estimated parameters for the bequest motive are both significant. This is important as bequests are a relevant factor in the savings decision. In contrast, our CRRA model, as well as the CRRA model in DeNardi, French, and Jones (2010), fails to identify a significant bequest motive. This again is related to the run-down of precautionary wealth after retirement. The low EIS implied by the CRRA model results in slow wealth deaccumulation, which is "confused" with the bequest motive, leading to identification problems.

The consumption floor is $20.1 \%$ of income. Here these parameters are fractions of overall mean income and thus are the same across education groups. Consequently, the floor is much closer to the mean income of the low

\footnotetext{
${ }^{20}$ Some studies, such as Attanasio and Paiella (2011) and Vissing-Jorgensen (2002b), consider a flow rather than a one-time cost of participation. We added a flow cost to the structural model. The point estimate turned out to be 0.00189 , and it was not significantly different from zero. Therefore we dropped it from the model.
} 
education group compared to others.

Overall, about $27 \%$ of households in the low education group hit the consumption floor. For each education, the chance of hitting the floor is much higher during retirement. $35 \%$ of the second group and $17 \%$ of the next to higher group hit the floor during retirement. Even the highest education group is supported through the floor during retirement in about $10 \%$ of the observations. The upper block of Table 5 reports the fraction of households that hit the consumption floor in the simulated data.

The CRRA model has a lower estimate of risk aversion, lower stock adjustment cost and higher consumption floor. In comparison, Alan (2006) estimates parameters to match the coefficients of a reduced form regression of participation on age and lagged participation. She estimates $\beta=0.92$ and a CRRA parameter of 1.6.

The lower estimate of risk aversion in CRRA model can be understood intuitively. Suppose the estimates of risk aversion is as high as that from EZW model, i.e., $\gamma=4.409$, then the implied EIS would be 0.227, much lower than the estimate of $\theta=0.601$. As a compromise, the estimated $\gamma$ from CRRA model is much lower than that from EZW model.

The standard CARA model predicts constant holding of risky assets, thus the stock share would be lower for the more educated households, inconsistent with the data. The problem can potentially be remedied by the stock adjustment cost, because low-income households care more about the cost. Consequently the CRRA model estimates a relatively higher $F$ compared to CRRA and EZW model. The estimated $\beta$ is lower, so that households accumulate less wealth and consequently care even more about the stock adjustment cost. As in the CRRA model, there is no significant bequest motive.

Table 3: Estimation Results

\begin{tabular}{c|ccccccccr}
\hline \hline & $\beta$ & $\gamma$ & $\Gamma$ & $F$ & $L$ & $\phi$ & $\underline{c}$ & $\theta$ & $£$ \\
\hline \hline EZWW & 0.862 & 4.409 & 0.010 & 0.020 & 0.031 & 1.834 & 0.201 & 0.601 & 212.69 \\
(baseline) & & & & & & & & \\
CRRA & $0.806)$ & $(0.156)$ & $(0.001)$ & $(0.002)$ & $(0.013)$ & $(0.443)$ & $(0.016)$ & $(0.017)$ & \\
& $(0.005)$ & $(0.035)$ & $(0.012$ & 0.012 & 0.128 & 0.730 & 0.318 & na & 1430.95 \\
CARA & 0.763 & 5.481 & 0.011 & 0.022 & 0.096 & 1.726 & 0.262 & na & 1061.35 \\
& $(0.008)$ & $(0.054)$ & $(0.001)$ & $(0.002)$ & $(2.751)$ & $(35.12)$ & $(0.01)$ & & \\
EZW(I) & 0.903 & 6.249 & 0.028 & 0.021 & 0.054 & 2.035 & 0.219 & 0.614 & 0.0618 \\
& $(0.27)$ & $(14.58)$ & $(0.215)$ & $(0.09)$ & $(0.396)$ & $(22.8)$ & $(0.377)$ & $(2.986)$ & \\
EZW(c) & 0.862 & 4.850 & 0.015 & 0.022 & 0.091 & 1.600 & 0.350 & 0.664 & 288.78 \\
& $(0.006)$ & $(0.223)$ & $(0.003)$ & $(0.003)$ & $(0.054)$ & $(0.395)$ & $(0.034)$ & $(0.041)$ & \\
\hline \hline
\end{tabular}

This table reports the estimated parameter values and fit (distance between model and data moments) for the CRRA, CARA and EZW preferences. The inverse of variances is used as weighting matrix, except in the case of EZW(I) where the identity matrix is used. The EZW(c) case, explained in the text, created moments by controlling for cohort rather than year effects. 


\subsubsection{Model Moments}

The moments of the estimated models are presented in two ways. First, Figure 4 graphs the life-cycle profiles estimated from simulated data as well as those from the actual data. This is done for the baseline EZW estimation. Table 4 presents the data moments and those produced by simulating the models at the estimated parameter values for all of the specifications in Table 3 .
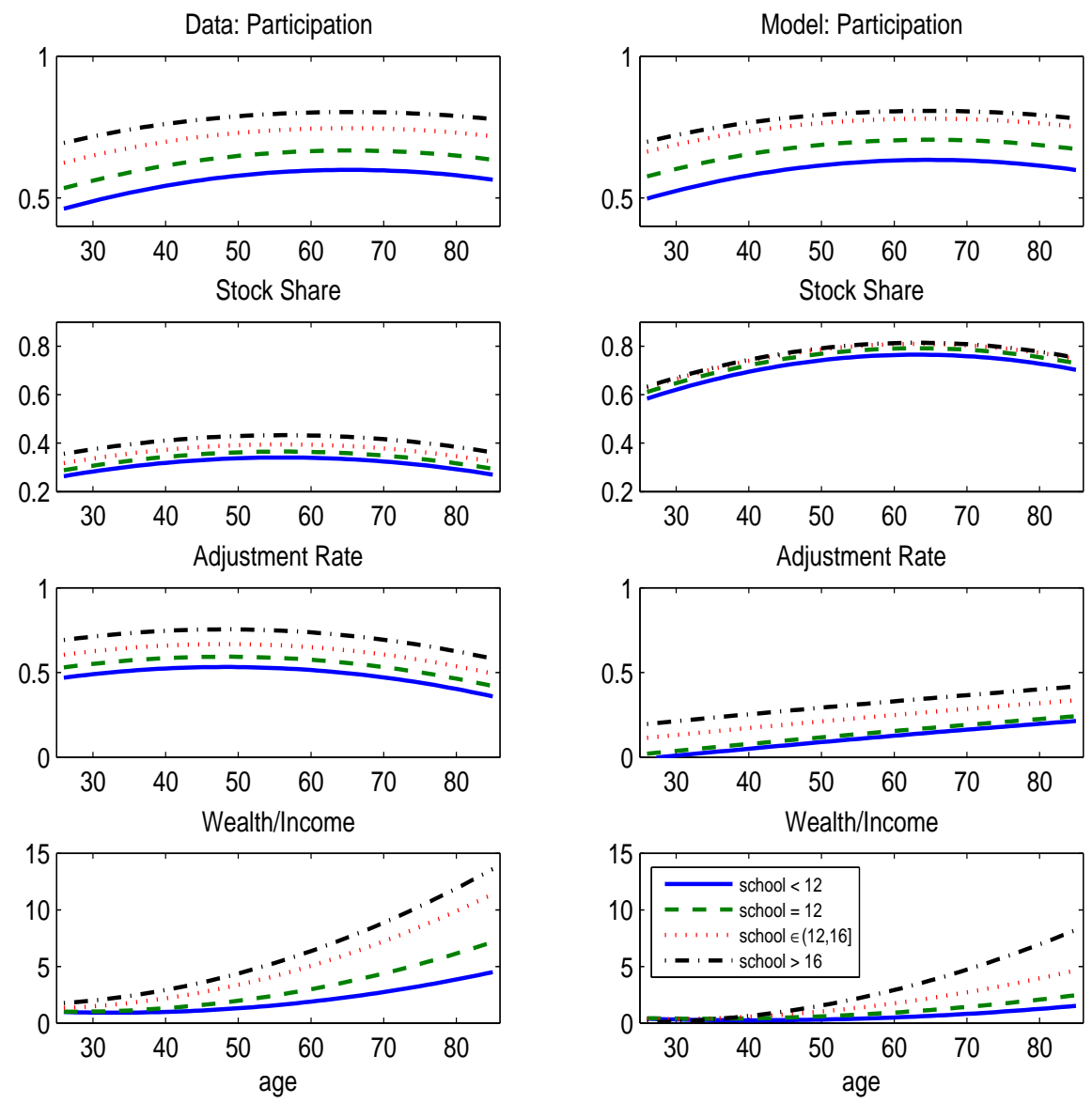

Figure 4: Profiles of Household Financial Decisions: Simulated Moments

These profiles show the age dependence of household financial decisions in the actual (left) and simulated (right) data. As with the actual data, the profiles from simulated data come from a linear regression with a constant, age, age-squared, and education dummies as independent variables. For the wealth-income regressions, the independent variables were a constant, age, age-squared and education dummies interacted with age and age-squared.

Looking at Figure 4, the left panel shows the data profiles and the right panel shows those from the estimated model. We evaluate the model fit both in terms of the affects of education and the life-cycle profile.

The model does a good job of capturing the affect of education on participation, stock share, adjustment rates and the wealth-income ratio: i.e. the difference of these choices across education groups is close to that in the data. The successful match is mainly driven by heterogeneity in mean income, coupled with costs associated with stock market, and non-homotheticity of preferences due to the consumption floor and the luxuriousness of a bequest. 
This point will be made clear later on.

The model succeeds in matching the participation profiles for all education groups. The low education group participates less and the high education group has the highest participation rates, for all ages. This good fit reflects the relatively high weight put on the participation moments by the weighting matrix, given in Table 15 .

Table 4: Moments from Simulated Data

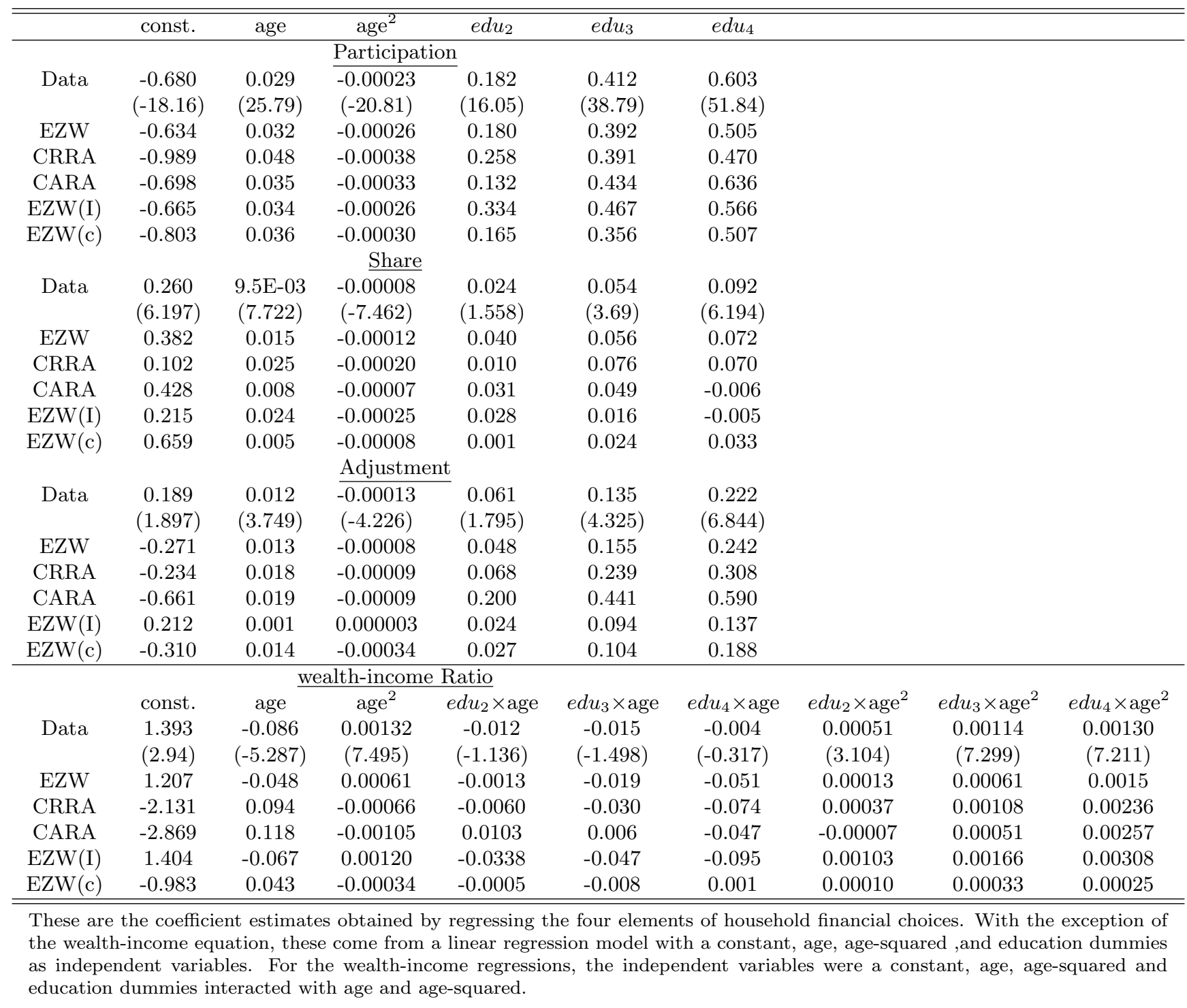

The model also captures the basic patterns for the stock share, the adjustment rates and the wealth-income ratios but misses on the levels of these choices. This partly reflects the weighting matrix that puts much less weight on the constant terms of these regressions relative to the coefficients on age, age-squared and education dummies. The predicted stock share is higher in the model than in the data. Two channels in the model can lower the stock share: higher stock adjustment cost and higher risk aversion. Both channels are disciplined by other 
moments that we try to match. A larger adjustment cost will deteriorate the match of stock average adjustment rate. Raising the degree of risk aversion jeopardizes the fit of education dummies, because a high $\gamma$ diminishes the roles of consumption floor and luxuriousness of bequests, hence reducing the non-homotheticity of the preferences.

Table 4 is informative about the ways in which the CRRA and CARA models fail to match the moments. As discussed earlier, the CRRA model implies a much lower EIS and hence much slower wealth deaccumulation, reflected in the much larger coefficient on age in the wealth-income ratio regression. In addition, a higher wealth level is associated with a higher participation rate and stock share, therefore the coefficients on age are also excessively large in the participation and share regression. Finally, the too-low deaccumulation of wealth after retirement trivializes the role of adjustment cost, consumption floor, and luxuriousness of bequests, impairing the ordering of participation and stock share by educational attainment. On the other hand, the slow deaccumulation of wealth generate wealth-income ratio profiles that are closer to the data than the EZW case. But this does not improve the overall fit much as the model puts more weights on participation moments than wealth-income ratio ones.

A main failing of the CARA model is in matching the stock share. Standard CARA model predicts constant holding of risky assets, implying a lower share for the more educated. Thus the coefficients on education dummies are not matched. The CARA model estimates a high adjustment cost and a lower $\beta$ which partly explains the too large gradient of adjustment rate with respect to educational attainment.

The model successfully generates wealth-income profiles that increase with age, implying slow deaccumulation of wealth as in DeNardi, French, and Jones (2010). Is this mainly driven by the bequest motive, or the level of medical expenses, or medical expense shocks? To answer the question, we shut down these channels one at a time. ${ }^{21}$

When the bequest motive is assumed not to exist, the wealth-income ratio falls to zero at age 67 for the least educated group, and at age 79 for the most educated. Consequently the model fit becomes much worse with $£=2408$. On the other hand, shutting down medical expense shocks changes the moments very little, except that the post-retirement stock share is slightly higher for each education group. Setting the level of medical expenses to zero does not worsen the model fit much either, with $£=258$. And the post-retirement wealth-income ratio profiles become steeper, because medical expenses no longer erode the wealth of households. In summary, the slow wealth deaccumulation is mainly driven by the bequest motive in our model.

Absent bequest motive, households run down assets quickly because they rely on the consumption floor to a large extent. This is clear from Table 5. During retirement, $62 \%$ of the least educated and $18 \%$ of the most educated rely on the consumption floor in the absence of a bequest motive. These numbers are significantly higher than in the baseline. In the absence of medical expense shocks, the overall chance of hitting the floor is slightly lower than the baseline.

In DeNardi, French, and Jones (2010), medical expense risks play a more important role in the slow deaccumulation of wealth after retirement. The difference largely comes from different parameterizations. DeNardi, French, and Jones (2010) ignores portfolio decisions and estimates a much higher $\beta$. In addition, because DeNardi, French, and Jones (2010) uses CRRA preferences, the estimated EIS (inverse of risk aversion) is much lower. These

\footnotetext{
${ }^{21}$ We are grateful to Dirk Krueger for suggesting this exercise.
} 
Table 5: Fraction of Households Hitting the Consumption Floor

\begin{tabular}{l|ccc}
\hline \hline & lifetime & pre-retirement & post-retirement \\
\hline & Baseline & & \\
\hline$e d u_{1}$ & 0.267 & 0.112 & 0.575 \\
$e d u_{2}$ & 0.119 & 0.003 & 0.352 \\
$e d u_{3}$ & 0.057 & 0.000 & 0.172 \\
$e d u_{4}$ & 0.034 & 0.000 & 0.102 \\
& No Bequest Motive & \\
\hline$e d u_{1}$ & 0.284 & 0.117 & 0.618 \\
$e d u_{2}$ & 0.136 & 0.004 & 0.400 \\
$e d u_{3}$ & 0.080 & 0.000 & 0.241 \\
$e d u_{4}$ & 0.059 & 0.000 & 0.176 \\
& No Medical Expenses Shocks & \\
\hline$e d u_{1}$ & 0.266 & 0.112 & 0.572 \\
$e d u_{2}$ & 0.122 & 0.002 & 0.361 \\
$e d u_{3}$ & 0.055 & 0.000 & 0.164 \\
$e d u_{4}$ & 0.034 & 0.000 & 0.102 \\
& No medical expenses & \\
\hline$e d u_{1}$ & 0.233 & 0.112 & 0.474 \\
$e d u_{2}$ & 0.066 & 0.002 & 0.194 \\
$e d u_{3}$ & 0.028 & 0.000 & 0.085 \\
$e d u_{4}$ & 0.019 & 0.000 & 0.057 \\
\hline \hline
\end{tabular}

The table reports the fraction of households who hit the consumption floor for each of the four education group. The numbers are the averages of lifetime, pre-retirement years and post-retirement years respectively.

parameter values make households willing to keep wealth levels high even if the bequest motive is weak, which also explains why the estimates of bequest parameters have large standard errors in DeNardi, French, and Jones (2010).

\subsection{Extensions and Robustness}

This section presents further estimation results to study an extension of the model to housing and the robustness of our parameter estimates.

\subsubsection{Housing}

Cocco (2005) and Yao and Zhang (2005), among other studies, stress the relevance of home-ownership on portfolio decisions. Thus far our model has excluded this important element of household financial decisions.

There are two approaches to extending the model to accommodate housing. The first approach, termed "Housing in Wealth" adds housing to both the model and data. In particular, we recompute the share and wealth-income ratio moments to include housing and amend the model to add housing to utility and to asset holdings. The second approach, termed "Housing out of Moments", extracts the effects of housing from the moments, and re-estimates the model. Overall, we find that neither of these treatments of housing influences our main findings regarding the effects of education on household financial decisions nor the parameter estimates. 
Table 6: Moments: Housing

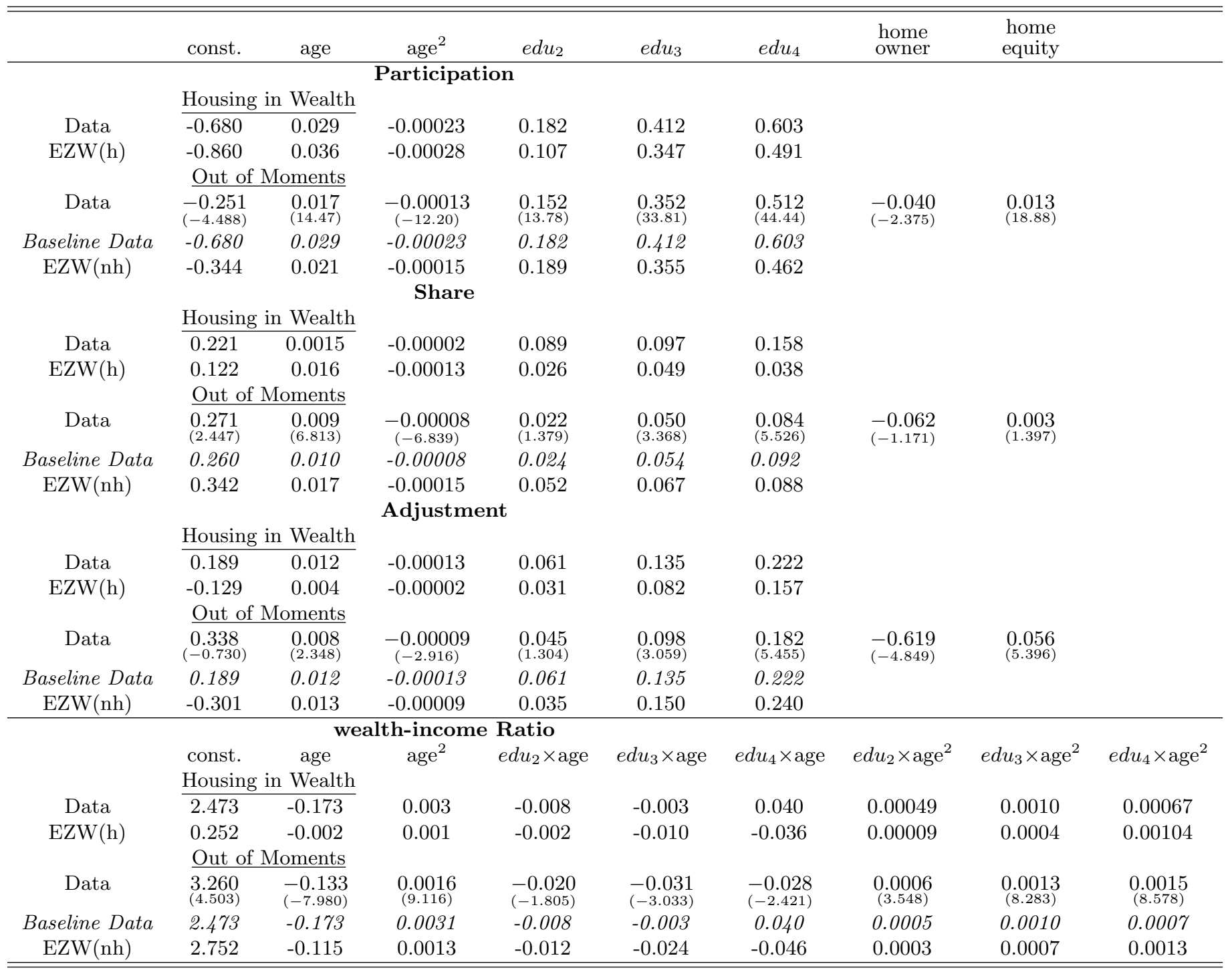

Model and data moments with housing treated. The 'Housing in Wealth' treatment adds housing to the measure of wealth, with home equity categorized as a bond. The 'Housing Controlled' treatment controls for the potential effects of housing on financial choices by including a dummy for home ownership and home equity to the regression equations. For ease of comparison, regression coefficients from the baseline are also reported in italics. For the wealth-income ratio regression, the coefficients on home ownership and home equity are $-1.704(7.80)$ and $0.129(13.95)$ respectively. Reported in the parentheses are t-statistics. 
Housing in Wealth This approach introduces housing into the model both as a consumption good and as an asset. Returning to the household choice problem, let $c$ represent the consumption flow of the household. As in Cagetti (2003), consumption is a composite of goods and services $(x)$ as well as the service flow from housing $(h)$. Assume a Cobb-Douglas function, $c=x^{\alpha} h^{1-\alpha}$, so that a constant fraction of expenditures is on housing services.

The return of housing as an asset has two components: price appreciation and (imputed) rental return. Various evidence shows that long-run price appreciation is low and the rental return is the major component. ${ }^{22}$ Since housing rent is relatively stable over time, the housing return resembles a bond. For this reason, and to ease computational burden, we combine housing asset with safe financial asset, and call this bundle of safe asset bond.

With housing treated as an safe asset, the return to bonds needs to be re-calibrated. First, we take housing return to be $5 \%$ per annum. As noted before, the majority of housing return comes from rental income. Campbell, Davis, Gallin, and Martin (2009) show that the rent-price ratio for the US residential market is about 0.05 on average, but appears to decline since the end of 1990s. Next, from SCF data, on average housing wealth is about $69.5 \%$ of total wealth. Therefore the return of composite bond-housing asset is $69.5 \% \times 5 \%+(1-69.5 \%) \times 2 \%=4.08 \%$.

Two sets of moments are re-calculated from SCF data with housing equity included - stock share in total wealth and wealth-income ratio. These new moments are reported in the block of Table 6 labeled "Housing in Wealth". Not surprisingly, looking at the regression constant, shares are much lower and wealth-income ratios are much higher than without housing (labeled 'Baseline Data' in the table). The life-cycle patterns though are roughly the same, and the ordering with respect to education remains.

The parameter estimates for this case are presented in Table 7 in the 'EZW(h)' row. Relative to the baseline estimates (reported in the first row of the table), the degree of risk aversion is higher when housing is included because the model attempts to match the lower stock share. A higher $\gamma$ implies a stronger precautionary motive and higher saving. The estimated $\beta$ is slightly lower relative to the baseline estimation, but the estimated $\theta$ is also lower, which helps generate more wealth accumulation. The other parameters are fairly close to the baseline.

The model does not fit the moments as well as the baseline. Generally, it is difficult for a rational expectations model to generate a low stock share. When housing is included in bonds, the stock share from the data is much lower than the baseline, posing a challenge to our model. In response to that, a high $\gamma$ is estimated. But as discussed earlier, a high $\gamma$ diminishes the role of parameters that make preferences non-homothetic. In addition, the average level of wealth is much higher in model with housing, which reduces the role of entry and fixed costs.

From Table 6, the simulated moments from the estimated model generally follows the same ordering by education as in the data. The exception is the stock share: the estimated model predicts a slightly lower share for the most educated group compared to the college graduates.

Housing Out of the Moments An alternative approach is to remove the effects of home-ownership and housing assets from data moments. That is, instead of adding housing to the model, we extract its influence from the data. Since our goal is to study the affects of education on financial choices, we are not directly interested in the affects

\footnotetext{
${ }^{22}$ For example, during 1987-2011, the Case-Shiller index at national level increased at an average rate of $0.285 \%$ per annum after inflation adjustment.
} 
Table 7: Estimation Results: Housing

\begin{tabular}{c|ccccccccr}
\hline \hline & $\beta$ & $\gamma$ & $\Gamma$ & $F$ & $L$ & $\phi$ & $\underline{c}$ & $\theta$ & $£$ \\
\hline \hline Baseline & 0.862 & 4.409 & 0.010 & 0.020 & 0.031 & 1.834 & 0.201 & 0.601 & 212.69 \\
& $(0.006)$ & $(0.156)$ & $(0.001)$ & $(0.002)$ & $(0.013)$ & $(0.443)$ & $(0.016)$ & $(0.017)$ & \\
EZW(h) & 0.837 & 4.712 & 0.013 & 0.019 & 0.042 & 1.539 & 0.171 & 0.554 & 390.71 \\
& $(0.003)$ & $(0.053)$ & $(0.001)$ & $(0.006)$ & $(0.013)$ & $(0.092)$ & $(0.003)$ & $(0.016)$ & \\
EZW(nh) & 0.853 & 4.429 & 0.008 & 0.022 & 0.033 & 0.290 & 0.220 & 0.629 & 155.98 \\
& $(0.006)$ & $(0.076)$ & $(0.002)$ & $(0.002)$ & $(0.008)$ & $(0.110)$ & $(0.017)$ & $(0.037)$ & \\
\hline \hline
\end{tabular}

This table reports the estimated parameter values and fit (distance between model and data moments) for the baseline and two housing models.

of housing on these choices.

To do this, we supplement the regressions presented in Table 2 with a dummy variable indicating home ownership and a measure of home equity. The resulting estimates are reported in the second block of Table 6 labeled 'Out of Moments'. Consistent with the findings in Cocco (2005) and Yao and Zhang (2005), including these controls changes the life-cycle profiles of household financial choices. As indicated in the table, being a homeowner reduces participation, stock share and the frequency of stock adjustment. In their simulation exercise, Cocco (2005) and Yao and Zhang (2005) find that home ownership crowds out stock holdings, which is supported by the negative coefficients on home ownership in our regression. The positive coefficients on home equity partly reflects a diversification benefit as home equity can be used to buffer financial and labor-income risks, a mechanism emphasized in Yao and Zhang (2005). Further, except for stock share, the estimated life-cycle profiles change as well.

However, the important patterns regarding the effect of education are not changed. For the stock share equation, the coefficients of education dummies are changed only marginally. Regarding participation, adjustment rate and wealth-income ratio, almost all the coefficients related to education dummies are smaller. Thus the education effect is somewhat weaker when housing is controlled, but it is still at about the same scale as the baseline.

The model is re-estimated using these regression coefficients as moments. By conditioning on housing, the coefficients on age, age-squared and the education dummies, which are our moments, differ from the baseline. Thus the parameter estimates will be different as well.

The parameter estimates are shown in the row labeled 'EZW(nh)' in Table 7. The estimated discount factor as well as the estimates of risk aversion and the EIS are very close to the baseline. The point estimate of the participation cost is slightly lower, which is consistent with the argument in Cocco (2005) that in the presence of housing, a lower fixed cost of equity market participation is needed to generate the empirically observed levels of participation.

The only significant change is the much lower estimate of $\phi$. That is, a bequest becomes less of a luxury and the preferences are less non-homothetic. This is partly in response to the weaker education effect on financial choices found in the data. The model fit is actually better than the baseline.

Looking at the moments, the ordering by education of participation, share and adjustment remain in both the 
estimated model and the data, conditioning on home ownership and equity. The estimated model also mimics the age dependence of these financial choices. But as in the baseline, we do not match the constant well. The stock share, adjustment rate and wealth-income ratio are lower in the simulated data.

\subsubsection{Identity Matrix}

The optimal weighting matrix is created by inverting the variance covariance matrix. As noted earlier, this procedure puts a lot of weight on the participation equation and less on other moments, such as the coefficients from the share and adjustment coefficients. ${ }^{23}$ Also it puts more weight on education dummies and less on the constant terms.

While the efficient weighting matrix puts more weight on moments that are more precisely estimated, it is interesting to see the parameter estimates under an alternative given the small sample. The row denoted EZW (I) in Tables 3 and 4 present estimates and moments for the EZW case where the weighting matrix, $W$, in (25) is the identity matrix. ${ }^{24}$ This weighting matrix produces consistent estimates, but is not as efficient in large samples.

For this treatment, the estimated discount factor and coefficient of risk aversion are higher than in the baseline as is the estimated degree of risk aversion. The participation cost is considerably larger as well. Other parameter estimates are relatively close to the baseline.

Looking at the moments, the constant coefficient from each regression is well matched to the data, but the coefficients on education dummies are much worse than the baseline model. This is because the identity matrix places considerably more weight on the constants. The good match for constants are achieved by the higher estimates for $\beta, \gamma$ and $\Gamma$. In other words, with plausible parameter values, our model is able to generate the mean levels of household finance variables.

\subsubsection{Cohort Effects}

As noted above, the regression model used to produce the moments for the estimation included controls for year effects. The underlying assumption was that cohort effects did not exist. But, as illustrated in Figure 1 the life-cycle profile of deterministic income was surely not independent of this identifying assumption. The same can be said for the moments reported in Table 2. Thus it is useful to study the robustness of our results to an alternative structure which controls for cohort rather than year effects.

To do so, the data moments reported in Table 2 were replaced with those calculated using a cohort dummy rather than a time dummy. The parameter estimates are reported in the row labeled 'EZW(c)' in Table 3. Compared to the baseline, the parameter estimates are not significantly different. The moments are provided in the last row of Table 4. The education effect is also close to that in the baseline, except that the education dummies for stock share regression are not matched as good as in the baseline. Thus the overall fit is slightly worse.

\footnotetext{
${ }^{23}$ As seen in Table 15, there is considerable variation across regressors. Due to the tiny scale of of coefficients on age-squared, they get a considerable amount of weight.

${ }^{24}$ With $W=I$ in $(25)$, the EZW model again outperformed the other preference specifications.
} 


\section{Heterogenous Parameters}

As indicated by the above results, agents in different education groups are induced to make different financial decisions. These differences arise solely from exogenous income, mortality and health expense processes. By assumption, the preferences and stock market entry/adjustment costs are the same across groups.

Yet one could conjecture that the discount factor, adjustment costs and other parameters could differ by education, or could be the factors that influenced education choice. ${ }^{25}$ All else the same, more patient people will go to school. And more educated people might face lower adjustment costs. In addition, differences in risk aversion might underlie the differential finance choices across education groups. In this section, we allow some unobservable heterogeneity.

The model is re-estimated using the same strategy and moments as in the baseline model, but allowing one parameter to be heterogeneous in each experiment. Five cases are considered, with heterogeneous $\beta, \gamma, \Gamma, F$ and $\theta$ respectively. Estimation results are reported in Table 8 and the moments are shown in Appendix Table 16. For each case of heterogeneity, estimates of education specific parameters are reported in the bottom part of the table. For ease of comparison, the top row of the table reports estimates from the homogenous (baseline) preferences model.

The heterogeneous entry cost model brings the most improvement in fit, from 212.69 in the baseline model down to 121.55 , as indicated in the last column of the table. The heterogeneous discount factor model also performs well, bringing the fit down to 139.83. The lower block of the table shows that higher education are associated with a lower entry cost and a higher discount factor.

Plausibly, individuals who receive higher education are endowed with higher cognitive ability. In addition, education could lead to reinforced learning ability, making it easier for individuals to search and grasp knowledge and skills need to participate in the stock market. These potential mechanisms are reflected in the decrease of $\Gamma$ with educational attainment. On the other hand, individuals who receive (or choose to receive) higher education could inherently be more patient, as captured by the increase of $\beta$ with educational attainment.

Heterogeneity in $\gamma$ does not improve the model fit significantly. This seems a little surprising given that the literature has attached so much importance to the differences in risk aversion. In fact one of the main motivation to introduce EZW preferences is to disentangle $\gamma$ from $\theta$, so that researcher could freely choose $\gamma$ to fit the asset pricing moments. The estimation results here are driven by differences in stock share and wealth-income ratio by education group. On the one hand, $\gamma$ needs to increase with educational attainment so that more educated households have higher precautionary saving hence match the wealth-income ratios. On the other hand, $\gamma$ needs to decrease with education so that more educated households would have higher stock shares. Due to the tension between these two mechanisms, the heterogeneous $\gamma$ cannot go too far to improve the model fit. Nevertheless, we find that the most educated households have significantly higher $\gamma$ than the least educated ones. Similarly, estimates in Cagetti (2003), based on the median wealth distribution, ranges from 4.3 for high school graduates to

\footnotetext{
${ }^{25}$ Haliassos and Michaelides (2003) assumes heterogeneity in risk aversion and argue that stock market participants may be more risk averse than non-participants. Gomes and Michaelides (2005) and Cagetti (2003) also have heterogeneous groups. Keane and Wolpin (2001) do not allow the discount factor to vary across individuals except for marital status.
} 
Table 8: Estimation Results: Heterogenous Parameters

\begin{tabular}{|c|c|c|c|c|c|c|c|c|c|}
\hline & $\beta$ & $\gamma$ & $\Gamma$ & $F$ & $\theta$ & $L$ & $\phi$ & $\underline{c}$ & $£$ \\
\hline Baseline & $\begin{array}{c}0.862 \\
(0.006)\end{array}$ & $\begin{array}{c}4.409 \\
(0.156)\end{array}$ & $\begin{array}{l}0.0103 \\
(0.001)\end{array}$ & $\begin{array}{l}0.0202 \\
(0.002)\end{array}$ & $\begin{array}{c}0.601 \\
(0.017)\end{array}$ & $\begin{array}{c}0.031 \\
(0.013)\end{array}$ & $\begin{array}{c}1.834 \\
(0.443)\end{array}$ & $\begin{array}{c}0.201 \\
(0.016)\end{array}$ & 212.69 \\
\hline Hetero $\beta$ & & $\begin{array}{c}4.141 \\
(0.052)\end{array}$ & $\begin{array}{c}0.0115 \\
(0.0027)\end{array}$ & $\begin{array}{c}0.0267 \\
(0.0048)\end{array}$ & $\begin{array}{l}0.701 \\
(0.05)\end{array}$ & $\begin{array}{l}0.092 \\
(0.04)\end{array}$ & $\begin{array}{c}0.692 \\
(0.189)\end{array}$ & $\begin{array}{c}0.167 \\
(0.034)\end{array}$ & 139.83 \\
\hline Hetero $\gamma$ & $\begin{array}{c}0.856 \\
(0.004)\end{array}$ & & $\begin{array}{c}0.0106 \\
(0.0009)\end{array}$ & $\begin{array}{c}0.0205 \\
(0.0028)\end{array}$ & $\begin{array}{c}0.600 \\
(0.022)\end{array}$ & $\begin{array}{c}0.025 \\
(0.009)\end{array}$ & $\begin{array}{c}1.608 \\
(0.371)\end{array}$ & $\begin{array}{c}0.192 \\
(0.014)\end{array}$ & 181.05 \\
\hline Hetero $\Gamma$ & $\begin{array}{c}0.859 \\
(0.006)\end{array}$ & $\begin{array}{c}4.170 \\
(0.271)\end{array}$ & & $\begin{array}{c}0.0297 \\
(0.0028)\end{array}$ & $\begin{array}{c}0.589 \\
(0.043)\end{array}$ & $\begin{array}{c}0.024 \\
(0.007)\end{array}$ & $\begin{array}{c}1.778 \\
(0.528)\end{array}$ & $\begin{array}{c}0.210 \\
(0.023)\end{array}$ & 121.55 \\
\hline Hetero $F$ & $\begin{array}{c}0.872 \\
(0.003)\end{array}$ & $\begin{array}{c}4.112 \\
(0.242)\end{array}$ & $\begin{array}{c}0.0116 \\
(0.0008)\end{array}$ & & $\begin{array}{c}0.642 \\
(0.024)\end{array}$ & $\begin{array}{c}0.049 \\
(0.018)\end{array}$ & $\begin{array}{c}1.609 \\
(0.321)\end{array}$ & $\begin{array}{c}0.208 \\
(0.007)\end{array}$ & 182.53 \\
\hline Hetero $\theta$ & $\begin{array}{c}0.857 \\
(0.006)\end{array}$ & $\begin{array}{c}4.536 \\
(0.098)\end{array}$ & $\begin{array}{c}0.0104 \\
(0.0014)\end{array}$ & $\begin{array}{c}0.0244 \\
(0.0028)\end{array}$ & & $\begin{array}{c}0.029 \\
(0.012)\end{array}$ & $\begin{array}{l}1.778 \\
(0.53)\end{array}$ & $\begin{array}{c}0.200 \\
(0.009)\end{array}$ & 173.03 \\
\hline & $\beta$ & $\begin{array}{c}\text { Educatic } \\
\gamma\end{array}$ & $\begin{array}{c}\text { specific } \\
\Gamma\end{array}$ & $\begin{array}{c}\text { arameters } \\
F\end{array}$ & $\theta$ & & & & \\
\hline$e d u_{1}$ & $\begin{array}{c}0.855 \\
(0.005)\end{array}$ & $\begin{array}{l}4.094 \\
(0.19)\end{array}$ & $\begin{array}{l}0.0161 \\
(0.003)\end{array}$ & $\begin{array}{c}0.0212 \\
(0.0023)\end{array}$ & $\begin{array}{c}0.620 \\
(0.048)\end{array}$ & & & & \\
\hline$e d u_{2}$ & $\begin{array}{c}0.855 \\
(0.007)\end{array}$ & $\begin{array}{c}4.697 \\
(0.396)\end{array}$ & $\begin{array}{l}0.0159 \\
(0.002)\end{array}$ & $\begin{array}{c}0.022 \\
(0.0030)\end{array}$ & $\begin{array}{c}0.588 \\
(0.028)\end{array}$ & & & & \\
\hline$e d u_{3}$ & $\begin{array}{c}0.865 \\
(0.006)\end{array}$ & $\begin{array}{l}4.253 \\
(0.51)\end{array}$ & $\begin{array}{l}0.0111 \\
(0.005)\end{array}$ & $\begin{array}{c}0.023 \\
(0.0026)\end{array}$ & $\begin{array}{c}0.564 \\
(0.018)\end{array}$ & & & & \\
\hline$e d u_{4}$ & $\begin{array}{c}0.874 \\
(0.004)\end{array}$ & $\begin{array}{c}4.686 \\
(0.073)\end{array}$ & $\begin{array}{l}0.0033 \\
(0.005)\end{array}$ & $\begin{array}{c}0.017 \\
(0.0026)\end{array}$ & $\begin{array}{c}0.557 \\
(0.020)\end{array}$ & & & & \\
\hline
\end{tabular}

This table reports the estimated parameter values and fit (distance between model and data moments) for EZW preferences allowing some parameters to differ by education group. Each part of the table allows heterogeneity in one parameter. The rows refer to the education groups: $e d u_{1}$ is less than 12 years, $e d u_{2}$ is 12 years, $e d u_{3}$ is between 12 and 16 and $e d u_{4}$ is more than 16 years of schooling.

2.4 for those not finishing high school.

Our estimates of the EIS decrease with educational attainment. On the contrary, the Euler equation estimation in Vissing-Jorgensen (2002a) and Vissing-Jorgensen and Attanasio (2003) yields higher EIS for stockholder relative to non-stockholders, and for wealthier households relative to poorer ones. These results are driven by the higher correlation between consumption growth and asset return for the wealthier stockholders. Our estimates of EIS is largely driven by the fact that more educated households run down assets more slowly hence have steep wealthincome profiles, which is captured by the lower EIS of the more educated who try to smooth more consumption into later stage of life. ${ }^{26}$

Gomes and Michaelides (2005) and Gomes and Michaelides (2008) show that households with higher EIS are more likely to participate in the stock market. A key assumption there is that the discount factor $\beta$ is sufficiently high, so that households generally prefer to save for the future, more so for those with high EIS. Our estimation consistently show that $\beta$ is much lower than one minus the rate of return on assets. As a result, households with

\footnotetext{
${ }^{26}$ Estimations in Vissing-Jorgensen (2002a) and Vissing-Jorgensen and Attanasio (2003) are based on linearized Euler equations, which entails strong assumptions regarding the correlation between asset return and labor income. In addition, consumption Euler equation does not hold when households refrain from portfolio rebalancing due to adjustment costs. It would be interesting to reconcile our results from those based on Euler equation using a structural framework.
} 
higher EIS would save less instead.

\section{Why Does Education Matter?}

Given these estimates, we return to a central question of the paper: what factors determine the different choices made by the disparate education groups? The analysis is in part motivated by the results of Campbell (2006) which indicated a role for both realized income and education in household choices.

We start with the case of homogenous parameters. As our analysis allows the processes for income, mortality and medical expenses to differ across education groups, even if two households have the same income realization, they may make different choices if they come from different income groups. In addition, we emphasize it is permanent income, rather than realized income, that matters most for household finance.

This section also discusses models of heterogeneous parameters, building on the results reported in Table 8. This allows us to study both observable and unobservable sources of differences across education groups simultaneously.

Our main finding is that the primary source of different financial decisions across education groups stems from higher income levels associated with education. Other differences, such as the discount factor and participation costs reported in Table 8, are not nearly as important.

\subsection{Homogenous Parameters}

We report two principal findings. First, the education specific mean level of income is a main source of differences in household financial decisions. Second, differences in the shape of income over working years, mortality rates and medical expenses are far less important.

Table 9 presents the detailed simulation results for alternative specification of income and medical expenses. These are simulation results using the baseline parameters for alternative specifications. There is no re-estimation. Each row of the table has a different treatment of mortality, income and medical expenses across education groups. In the baseline model, all of these processes differ across education groups.

The "Same Determ. Inc." treatment forces all education groups to have the same mean income profile. The "Same Stoch. Inc." treatment assumes that all education groups have the same variances of income shocks. The "Same Income Shape" case imposes the same life-cycle pattern on all groups but keeps the mean level of income heterogeneous. The "Same Medical Exp." treatment forces all education groups to have the same average expenditure relative to post-retirement income. The "Same Mortality" treatment forces all education groups to have the same mortality rates.

For each of these treatments, the process for the lowest education group is used as the common element of the process. So, for example, in the "Same Determin. income" treatment, all education groups have the profile of the lowest education group. This choice of using the profile of the lowest education group is simply to provide a basis of comparison.

As this table makes very clear, the difference in deterministic income is the major factor explaining the diverse 
Table 9: Exogenous Processes and the Effects of Education

\begin{tabular}{|c|c|c|c|c|c|c|c|c|c|}
\hline & const. & age & age $^{2}$ & $\mathrm{edu}_{2}$ & $\mathrm{edu}_{3}$ & $\mathrm{edu}_{4}$ & & $£$ & \\
\hline \multicolumn{10}{|c|}{ Participation } \\
\hline Baseline & -0.634 & 0.032 & $-0 . \overline{00026}$ & 0.180 & 0.392 & 0.505 & & 212.69 & \\
\hline Same Determ. Inc. & -0.317 & 0.022 & -0.00019 & -0.053 & -0.037 & 0.024 & & 5323.4 & \\
\hline Same Stoch. Inc. & -0.625 & 0.034 & -0.00029 & 0.282 & 0.425 & 0.562 & & 402.50 & \\
\hline Same Income Shape & -0.743 & 0.035 & -0.00027 & 0.170 & 0.372 & 0.452 & & 337.3 & \\
\hline Same Med. Exp. & -0.645 & 0.033 & -0.00027 & 0.174 & 0.382 & 0.501 & & 246.63 & \\
\hline Same Mortality & -0.636 & 0.031 & -0.00025 & 0.200 & 0.412 & 0.519 & & 205.58 & \\
\hline \multicolumn{10}{|c|}{ Stock Share } \\
\hline Baseline & 0.382 & 0.015 & -0.00012 & 0.040 & 0.056 & 0.072 & & & \\
\hline Same Determ. Inc. & 0.196 & 0.018 & -0.00011 & -0.008 & -0.012 & -0.009 & & & \\
\hline Same Stoch. Inc. & 0.158 & 0.022 & -0.00017 & -0.004 & 0.049 & 0.044 & & & \\
\hline Same Income Shape & 0.322 & 0.016 & -0.00013 & 0.035 & 0.047 & 0.078 & & & \\
\hline Same Med. Exp. & 0.388 & 0.014 & -0.00012 & 0.039 & 0.055 & 0.068 & & & \\
\hline Same Mortality & 0.356 & 0.016 & -0.00013 & 0.040 & 0.051 & 0.061 & & & \\
\hline \multicolumn{10}{|c|}{ Adjustment Rate } \\
\hline Baseline & -0.271 & 0.013 & $-7.65 \mathrm{E}-05$ & 0.048 & 0.155 & 0.242 & & & \\
\hline Same Determ. Inc. & 0.019 & 0.000 & $4.94 \mathrm{E}-05$ & -0.064 & -0.035 & 0.030 & & & \\
\hline Same Stoch. Inc. & -0.231 & 0.012 & $-7.89 \mathrm{E}-05$ & 0.089 & 0.188 & 0.278 & & & \\
\hline Same Income Shape & -0.288 & 0.013 & $-8.35 \mathrm{E}-05$ & 0.025 & 0.134 & 0.199 & & & \\
\hline Same Med. Exp. & -0.273 & 0.013 & $-7.47 \mathrm{E}-05$ & 0.050 & 0.160 & 0.243 & & & \\
\hline Same Mortality & -0.258 & 0.012 & $-7.62 \mathrm{E}-05$ & 0.048 & 0.153 & 0.229 & & & \\
\hline \multicolumn{10}{|c|}{ wealth-income } \\
\hline & const. & age & age $^{2}$ & $\begin{array}{l}\text { age } \times \\
\text { edu }_{2}\end{array}$ & $\begin{array}{c}\text { age } \times \\
\text { edu }_{3}\end{array}$ & $\begin{array}{c}\text { age } \times \\
\text { edu }_{4}\end{array}$ & $\begin{array}{c}a g e^{2} \times \\
\mathrm{edu}_{2}\end{array}$ & $\begin{array}{c}\operatorname{age}^{2} \times \\
\mathrm{edu}_{3}\end{array}$ & $\begin{array}{c}\operatorname{age}^{2} \times \\
\mathrm{edu}_{4}\end{array}$ \\
\hline Baseline & 1.207 & -0.048 & 0.00061 & -0.0013 & -0.019 & -0.051 & 0.00013 & 0.00061 & 0.0015 \\
\hline Same Determ. Inc. & -0.018 & -0.001 & 0.00021 & 0.0056 & 0.006 & 0.008 & -0.00017 & -0.00017 & -0.0001 \\
\hline Same Stoch. Inc. & 1.216 & -0.048 & 0.00061 & 0.0036 & -0.015 & -0.047 & 0.00012 & 0.00060 & 0.0013 \\
\hline Same Income Shape & 1.849 & -0.072 & 0.00081 & -0.0063 & -0.027 & -0.038 & 0.00019 & 0.00070 & 0.0010 \\
\hline Same Med. Exp. & 0.862 & -0.035 & 0.00049 & -0.0005 & -0.016 & -0.046 & 0.00011 & 0.00056 & 0.0014 \\
\hline Same Mortality & 1.923 & -0.075 & 0.00084 & -0.0069 & -0.037 & -0.071 & 0.00026 & 0.00102 & 0.0019 \\
\hline
\end{tabular}

This table reports the model moments from counter-factual exogenous processes. "Same Determ. Inc." case imposes the same deterministic income of the least educated group on the remaining three. "Same Stoch. Inc." uses the stochastic income process of the least educated for the other three groups. "Same Income Shape" imposes the shape of life-cycle income profile of the least educated to the other groups, but keeps the levels of lifetime income different between education groups. "Same Med. Exp" uses the out-of-pocket medical expenses of the lowest income group for all groups. "Same Mortality" uses the mortality rates of the lowest education group for all groups. The simulations are based upon the baseline estimates from the EZW preferences. Fit is computed from (25) for the various cases.

financial decisions across education groups. This is seen from the column of Table 9 labeled $£$, which shows how well the model fits the moments under the alternative processes. The fit in the "Same deterministic income" treatment is over 20 times worse than the baseline. The fit for the other treatments worsened but not by the same magnitude, except the case of same mortality where the fit increases slightly.

The key to understanding how the different processes influence household decisions is through the patterns for the education dummies in Table 9. When all households have the same deterministic income, the differences in participation, portfolio share and portfolio adjustment essentially disappear across education groups relative to the baseline. This is also true for the wealth-income ratio where age effects are interacted with education dummies hence harder to read. 
Why does the Income Level Matter? Education matters for household finance mainly because it increases the income level. But what are the underlying mechanisms? Three channels are potentially important. First, income is the stable stream of return on human capital, and thus partially substitutes for bond holdings, as shown in Heaton and Lucas (1997). This income substitution effect should be stronger for higher income households, leading to higher stock share, which in turn could affect wealth-income ratio because higher stock share implies higher return on investment. Second, high income diminishes the entry cost and stock adjustment cost which are fixed rather than being proportional to income or wealth. This "fixed cost effect" induces higher participation rate and stock share for the higher-income households. Third, the consumption floor and the luxuriousness of a bequest (as measured by the parameter $\phi$ ) induce a lower stock share but a higher wealth-income ratio for higher-income households who rely less on the floor and care more about the riskiness of bequeathed assets.

We perform three experiments to understand the relative importance of these channels. In experiment one, we set $\Gamma=0$ and $F=0$, with other parameters taken from the baseline estimation, so that the fixed cost affects are shut down. In experiment two, in addition to $\Gamma=0$ and $F=0$ we set $\underline{c}=0$. Finally in experiment three, we further set $\phi=0$, so that the aforementioned channel two and three are both shut down.

Table 10: The Roles of Non-proportional Parameters

\begin{tabular}{l|ccc}
\hline \hline & $\mathrm{edu}_{2}$ & $\mathrm{edu}$ & $\mathrm{edu}_{4}$ \\
\hline Baseline & \multicolumn{3}{|c}{ stock share } \\
$\Gamma=0, F=0$ & 0.040 & 0.056 & 0.072 \\
$\Gamma=0, F=0, \underline{c}=0$ & -0.053 & -0.071 & -0.078 \\
$\Gamma=0, F=0, \underline{c}=0, \phi=0$ & -0.015 & 0.058 & 0.075 \\
& -0.016 & 0.063 & 0.085 \\
& \multicolumn{3}{|c}{ wealth-income } \\
\hline Baseline & 0.363 & 1.016 & 2.093 \\
$\Gamma=0, F=0$ & 0.399 & 0.985 & 2.037 \\
$\Gamma=0, F=0, \underline{c}=0$ & 0.006 & 0.392 & 1.294 \\
$\Gamma=0, F=0, \underline{c}=0, \phi=0$ & -0.338 & -0.207 & 0.662 \\
\hline \hline
\end{tabular}

The table reports the differences in stock share and wealth-income ratio of education group two, three, four relative to group one in various experiments.

Table 10 reports the stock shares and wealth-income ratios of education group two, three, and four relative to group one. ${ }^{27}$ Essentially, these moments are coefficients for education dummies when we regress stock share or wealth-income ratio on a quadratic function of age and the education dummies. For comparison, we also report the moments from the baseline model.

In the absence of costs $(\Gamma=0$ and $F=0)$, the model generates an ordering of stock share which is exactly the opposite of that in the data. Thus the costs play an critical role. Without these costs, the income substitution effect is dominated by the roles of the consumption floor and bequests. However when $\underline{c}=0$ and $\phi=0$, more educated households clearly have higher stock share, except that education group two has slightly lower stock share than group one, which is due to the higher medical expenses of group two relative to group one. In summary, it is

\footnotetext{
${ }^{27}$ With zero costs, participation rate for each group is basically $100 \%$. Theoretically the adjustment rate is also $100 \%$, but it is below $100 \%$ due to computational error.
} 
the joint force of income substitution effect and fixed cost effect that delivers the observed ordering of stock share by educational attainment.

Regarding the wealth-income ratio, the zero costs case delivers almost the same ordering by education as the baseline model. That is, the costs do not play a significant role in the ordering of wealth-income ratio, although they induce higher stock shares hence higher investment return for the more educated. The ordering becomes much weaker when $\underline{c}=0$, and it disappears when $\phi=0$. Clearly, wealth-income ratio increases with educational attainment mainly because the higher-income households rely less on the consumption floor and care more about bequests.

\subsection{Heterogenous Parameters}

Returning to the quantitative importance of various education-related attributes to household finance, Table 11 reports the fits for various combinations of preferences specifications (columns) and restrictions on differences across education groups (rows). So, for example, the 'Same Stochastic Inc.' row and the 'Hetero $\gamma$ ' column combines the estimates reported in Table 8 with the restriction, as in Table 9, that all households have the same stochastic income as the low education group. The entry in the table is the model fit for that case.

The row of "same parameter" takes the estimated parameters from Table 8, but assumes households have homogeneous preferences. For example, in the heterogeneous $\beta$ case, the "same parameter" treatment imposes the $\beta$ of education group one on the remaining groups. This parameterization differs from the baseline since the other parameters differ once heterogeneity is allowed in one dimension. That is, for example, in the heterogeneous $\beta$ case reported in Table 8, the estimates of all the other parameters differ from the baseline as well.

Table 11: Model Fit for Heterogeneous Preferences Cases

\begin{tabular}{l|ccccc}
\hline \hline & Hetero $\beta$ & Hetero $\gamma$ & Hetero $\Gamma$ & Hetero $F$ & Hetero $\theta$ \\
\hline Full Model & 139.83 & 181.05 & 121.55 & 182.53 & 173.03 \\
Same Determ. Inc. & 4280.20 & 5043.16 & 4655.08 & 5177.15 & 4834.31 \\
Same Stocha. Inc. & 311.97 & 410.29 & 219.36 & 370.13 & 374.16 \\
Same Income Shape & 174.86 & 281.05 & 218.92 & 285.82 & 245.04 \\
Same Med. Exp. & 155.11 & 204.78 & 131.32 & 209.21 & 185.70 \\
Same Mortality & 169.74 & 199.66 & 171.42 & 186.81 & 222.86 \\
Same Parameter & 279.63 & 296.24 & 217.26 & 192.03 & 265.71 \\
\hline \hline
\end{tabular}

The table reports the distance between model and data moments from various heterogeneous preferences models, and from counter-factual exogenous processes. The "Same Parameter" imposes the preference parameter of the least educated group to all the households, hence the models return to a homogeneous preferences one.

As reported above, differences in deterministic income remain the dominating factor: the fit explodes when the deterministic income profiles of the least educated is imposed on other groups. Comparing the fit from the "same parameter" case to the full model, it is evident that preference heterogeneity account for only a small fraction of the difference in households finance. 


\section{Conclusion}

This paper studies household financial decisions for different education groups. Patterns of household finance, including participation in asset markets, portfolio shares, stock adjustment rates and wealth to income ratios, differ across education groups. One contribution is to study these patterns jointly.

A main contribution of the paper is to estimate a structural model that maps education-related differences to household financial decisions. This mapping goes through a dynamic choice model in which households face uncertainty in income and stock returns, and make costly decisions regarding asset market participation as well as portfolio adjustment.

Based on the rich patterns of household finance, we estimate adjustment costs, the discount factor and three common utility functions: constant relative risk aversion, constant absolute risk aversion and recursive utility. The recursive utility representation of household preferences fits the data best.

Among the observable education specific factors, the important difference across households is their mean income. More educated households have higher mean income and this translates into a higher rate of asset market participation, higher stock share in wealth, a higher adjustment rate and a higher wealth to income ratio. Other observable factors, including income uncertainty, shape of income profile, mortality and medical expenses, have little power in explaining different household finance patterns across education groups. Among the various specifications with unobservable heterogeneity, we find that the more educated groups discount the future less and have lower participation costs than the less education groups.

There are a couple of areas for further research based upon our findings. First, while housing is studied, the potential costs associated with adjustments in the stock of housing are not included. This is partly due to tractability problems from having too large of a state space. Adding housing with its own adjustment costs to an optimization problem with costs of stock adjustment would be of considerable interest.

Second, the model is estimated using moments aggregated across households. It would be of interest to complement this exercise using moments created from individual decisions. For example, using data that include household choices of adjustment, participation etc. as well as relevant state variables, one could create moments from estimating an approximate decision rule and then use these moments to estimate structural parameters.

Finally, the current model can be extended to a general equilibrium one, and used to study its policy implications. An interesting policy experiment would be to reduce the level and uncertainty of out-of-pocket medical expenses, which mimics "Obamacare", and study its impact on savings, portfolio choice and asset prices. 


\section{$9 \quad$ Appendix}

\subsection{Exogenous Processes}

Income process before retirement We estimate household's income process from the PSID during the period of 1989-2009, corresponding to the time periods from which we construct household finance moments. ${ }^{28}$ Compared with most of the relevant studies, we include more recent waves of the survey. Household income is defined as the sum of labor income of both spouse and transfers, adjusted for inflation based on CPI, so that income is in 1998 dollar before being re-scaled.

From the PSID, we extract a balanced panel of 1245 households. Households with the following traits are excluded: (i) in low-income (SEO) subsample (ii) with invalid information on age, education, and race of head (iii) younger than 30 or older than 65 in 2009, the last wave of survey (iv) zero income in any year (iv) income growth below $1 / 20$ or over 20 in any year.

To estimate the deterministic income profile and stochastic processes of income, we break the data into four education groups. For each education group, data from various years are pooled together. Then the logarithm of income is regressed on age dummies, year dummies and dummies for race.

The education specific deterministic income profile comes from the coefficients of age dummies, re-scaled so that average income equals education specific average income. Then we pool the income profiles of the four education groups together, re-scaled the data again, so that the mean income of the four groups equals one. The profiles in Figure 1 are the smoothed versions. We use a Hodrick-Prescott filter with smoothing parameter of 400 .

It should be noted that the deterministic income profiles are a mixture of age effect and cohort effect. In the dummy regression, year effect is specifically controlled for. Due to the well-known identification problem among year effect, cohort effect and age effect, we are unable to control for cohort effects once year effects are in the regression.

The residuals from the regression, denoted $y_{i, t}$ are assumed to be income shocks that follows the stochastic process in equation(4) To estimate $\rho, \sigma_{\epsilon}^{2}$ and $\sigma_{\eta}^{2}$, we employ the standard minimum distance method, matching the variance-covariance of $\left\{y_{i, t}\right\}$ from the econometrics model with that in the data. For details about moments construction and estimation method, see Guvenen (2009).

Medical Expenses Information on medical costs is based on University of Michigan Heath and Retirement Study (HRS). This is a longitudinal panel study that surveys a representative sample of more than 26,000 Americans over the age of 50 every two years. Supported by the National Institute on Aging and the Social Security Administration. Out-of-pocket medical expense is defined as the sum of what the household spends on insurance premia, drug costs, and costs for hospital, nursing home care, doctor visits, dental visits, and outpatient care. The waves of survey used in this paper are: 1996, 1998, 2000, 2002, 2004, 2006 and 2008.

We assume the same stochastic process for each education group, and take the persistence and variances of shocks directly from French and Jones (2004). The variance of transitory shocks is large with $\sigma_{\epsilon_{M}}^{2}=0.442$. The

\footnotetext{
${ }^{28}$ The survey has been bi-annual since 1997.
} 
variance of the persistent shocks is $\sigma_{\eta_{M}}^{2}=0.0503$ with serial correlation of $\rho_{M}=0.922$. Importantly, the same process applies for each education group. Deterministic out-of-pocket medical expenses differ significantly cross education groups.

For our model we need the ratio of out-of-pocket expenditure over post-retirement income. To estimate the profiles of this ratio, we take the data used in French and Jones (2004). Educational attainment information is not available from the online data of French and Jones (2004), so we obtain it from HRS website (http: //hrsonline.isr.umich.edu/) and merge it with other variables by matching household identities. From the match data we delete respondents whose ratio is not positive or greater than 10. Totally there are 11866 respondents. We regress the ratio on age, age-squared, income, income-age interaction, education dummies and the interaction of education dummies with age. In the structural model, we use these regression coefficients to predict out-of-pocket medical expenses for household's optimization problem.

Death Probability Following the method in DeNardi, French, and Jones (2006), we estimate survival probability as a function of age, age-squared, income, and education dummies, then calculate death probability (conditional on survival) as one minus survival probability. We take the data used in DeNardi, French, and Jones (2006), and augment it with educational attainment information from HRS via matching household identities. ${ }^{29}$.

Asset Returns The return process for stocks is taken from Robert Shiller's online data of $S \& P 500$ for the period 1947-2007. The return is defined as the sum of annual dividend return and capital gain, deflated by CPI. The estimated mean and standard deviation of annual stock return are $6.33 \%$ and $15.5 \%$ respectively. The return on bonds is assumed to be non-stochastic and is set at $2 \%$ annually.

\subsection{Moments}

The moments are summarized in Table 2. Their definitions follow.

\subsubsection{Participation, stock share and wealth-income ratio}

We obtain household level stock market participation, stock share in financial wealth for stockholders and median wealth-income ratio from seven waves of Survey of Consumer Finances: 1989, 1992, 1995, 1998, 2001, 2004 and $2007{ }^{30}$ From each wave of survey, data with one of the following traits are excluded: (i) not having valid information on asset holding, non-asset income, age of head, and educational attainment of head; (ii) stock holding being negative; (iii) bond holding being non-positive; (iv) house-heads is younger than 25 or older than 85 . Table 12 presents the basic information on data from the SCF.

\footnotetext{
${ }^{29}$ We are grateful to Eric French for sharing the data and stata code with us.

${ }^{30}$ We also obtain the two profiles from PSID data introduced below. The resulting profiles have very similar shape as in SCF, but of different scales. For example, the mean stock market participant rate for working households is $47.6 \%$ in PSID, but it is $59.2 \%$ in SCF. For working households, the mean stock share is $44.2 \%$ in PSID, but $70.3 \%$ in SCF. The major reason for such differences should come from different sampling strategy. In addition to a standard multistage area-probability design, which leads to a representative sample, $\mathrm{SCF}$ selects a second sample based on tax data from the Statistics of Income Division of the Internal Revenue Service, which leads to a representative sample of approximately 1,500 high-wealth households. Consequently, SCF has a larger sample of wealthier households.
} 
Table 12: Basic statistics of SCF data

\begin{tabular}{lccccccc}
\hline & Table 12: Basic statistics of SCF data & & \\
\hline \hline Survey year & 1989 & 1992 & 1995 & 1998 & 2001 & 2004 & 2007 \\
\hline sample size & 1,393 & 2,457 & 3,632 & 3,728 & 3,966 & 4,011 & 3,923 \\
mean age & 56.6 & 43.1 & 49.5 & 49.5 & 49.7 & 50.3 & 51.0 \\
mean participation rate & 0.501 & 0.496 & 0.500 & 0.548 & 0.564 & 0.559 & 0.575 \\
median wealth-income & 1.391 & 0.350 & 0.337 & 0.479 & 0.683 & 0.555 & 0.602 \\
mean stock share (participants) & 0.379 & 0.501 & 0.543 & 0.627 & 0.606 & 0.578 & 0.581 \\
\hline \hline
\end{tabular}

We define stock as the sum of three categories: (i) publicly trade stock (including those with brokerage account, employment related stock and foreign stock) (ii) mutual fund and trust or managed investment account that are investment in equity market (iii) IRA and annuity. Part of IRA and annuity may not be invested in equity, but we include them in our definition of stocks because these assets are costly to adjust, which is consistent with our model definition of stock. We define bonds as the sum of assets in two broad categories: (i) checking account, savings account, CDs, bond market account and whole insurance (ii) mutual fund and trust or managed investment account that are investment in bond markets or CDs.

To bring assets in mutual fund and trust or managed investment account into our definition of stock and bond, we follow Gomes and Michaelides (2005). Specifically, based on the answer of respondents to survey question "how is [this money] invested?", if most of the asset is in stocks, then it is included in our definition of stock. If most of the asset is in bonds or money market or CDs, it is included in our definition of bond. If the investment is reported as a combination or mixed or diversified, then half of that asset is included in stock and the other half in bond. For other answers to the survey, we assume the asset is non-financial. ${ }^{31}$

Our definition of stocks and bonds covers the majority of financial assets held by US households. We define stock market participants as those who own have positive stockholding by our definition. For the participants, we define stock share in financial wealth as $\frac{\text { stock }}{\text { stock+bond }}$. Both stockholding and bondholding are adjusted to 1998 dollar based on CPI urban series.

To compute median-income ratio, we define income as total family income minus asset income reported in SCF. The following are included as asset income: income from non-taxable investments such as municipal bonds, income from dividends, income from stock, bond and real estate and other interest income.

\subsubsection{Treatment of housing}

As one way to deal with housing, we include housing asset in the measurement of wealth. The SCF provides information about the self-reported market value of home at the time of interview. Also reported is the amount of mortgage related to home, including the second or third mortgage. We define home equity as the difference between home value and mortgage. In the pooled sample, about $3 \%$ of households have negative home equity. For homeowners, home equity on average accounts for $53 \%$ of their total wealth. For homeowners who participate in the stock market, home equity accounts for $39 \%$ of their total wealth.

\footnotetext{
${ }^{31}$ Other ways of investment include life insurance, fixed contract, annuities, tangible assets other than real estate, intangible assets, business investments and others.
} 
Table 13: Basic statistics of PSID data used to estimate adjustment rate

\begin{tabular}{lcccc}
\hline \hline Survey year & 2001 & 2003 & 2005 & 2007 \\
\hline sample size & 2496 & 2541 & 2473 & 2518 \\
mean age & 47.4 & 47.8 & 48.5 & 48.8 \\
mean adj. rate & 0.639 & 0.574 & 0.577 & 0.581 \\
\hline \hline
\end{tabular}

For this housing in wealth case, we re-calculate stock share and wealth-income ratio based on the new definition of wealth: the sum of stock, bond and home equity. Since home equity is treated as a safe asset, the stock share is lower compared to the baseline, and wealth-income ratio is higher.

\subsubsection{Adjustment rate}

We obtain stock adjustment rate of stockholders from four waves of Panel Study of Income Dynamics: 2001, 2003, 2005, 2007. Starting from 1997, PSID survey includes a set of questions regarding households' wealth status and its dynamics since last survey. These questions enable us to estimate adjustment rate for each education group. Stockholders are defined in a similar way as with SCF data. Stock is defined as the sum of "non-IRA stock (variables ER15007 ER19203 ER22568 ER26549 ER37567)" and "IRA/annuity (variables ER15014 ER19210 ER22590 ER26571 ER37589)". Since we are obtaining stock adjustment information for stockholders, households with zero stockholings are dropped from the sample. Low income families (SEO subsample), as well as those with invalid information on stockholding and stock adjustment are also dropped. Finally, in each wave of survey we drop households whose heads are either younger than 20 or older than 80. Basic statistics about the data are presented in Table 13.

PSID asks a set of questions about the changes in stock account. For non-IRA stocks, it asks the following questions:

(i) "[Since January of last survey], did you (or anyone in your family) buy any shares of stock in publicly held corporations, mutual funds, or investment trusts, including any automatic reinvestments-not including any IRAs?" (ii) "Did you (or anyone in your family) also sell any such assets?"

(iii)" Did you buy more or sell more-that is, on balance, did you put money into stocks, mutual funds, or investment trusts, take money out of them, or put about as much in as you took out?"

For IRA and annuity, the following questions are asked:

(i) "[Since January of last survey], did you (or your family) put aside money in any private annuities or IRAs?"

(ii) "did you (or anyone in your family) cash in any part of a pension, private annuity, or IRA?"

We define household level adjustment as a binary variable. The variable is assigned "1" if a household reported to have bought or sold shares in non-IRA stock, or have put aside money in or cash in private annuities or IRAs. It should be noted that our definition is the "net adjustment", in the sense that it excludes the adjustment of individual stocks within the stock portfolio, whether it is done by the household or mutual fund manager. 


\subsection{Initial Distribution}

As noted earlier, the quantitative analysis requires an initial distribution of asset holdings. Table 14 summarizes the initial asset allocation by education group. Both average stock and bond holdings are positively correlated with the level of educational attainment. The initial participation rate and stock shares are also higher for the high education group.

Table 14: Initial Asset Allocation By Education

\begin{tabular}{c|cccc|cc}
\hline \hline Schooling & $\begin{array}{c}\text { Stock } \\
(1998 \$)\end{array}$ & $\begin{array}{c}\text { Bond } \\
(1998 \$)\end{array}$ & Stock/Income & Bond/Income & Participation & $\begin{array}{c}\text { Stock Share } \\
\text { (participants) }\end{array}$ \\
\hline \multicolumn{7}{|c|}{ Means } \\
\hline$<12$ & 81.37 & $1,951.39$ & 0.003 & 0.091 & 0.032 & 0.425 \\
$\in(12,16]$ & 776.71 & $3,334.41$ & 0.035 & 0.160 & 0.137 & 0.493 \\
$>16$ & $3,941.72$ & $6,459.67$ & 0.169 & 0.301 & 0.299 & 0.498 \\
\hline \multicolumn{7}{|c|}{ Standard Deviations } \\
\hline$<12$ & $6,118.96$ & $8,812.79$ & 0.421 & 0.399 & 0.538 \\
\hline$=12$ & $3,836.69$ & $8,966.91$ & 0.025 & 0.225 & & \\
$\in(12,16]$ & $13,824.92$ & $13,099.07$ & 0.174 & 0.581 & 0.633 & \\
$>16$ & $15,894.16$ & $12,402.11$ & 0.668 & 0.557 & & \\
\hline \hline
\end{tabular}

This table reports the initial holdings of stock and bonds by education group. Within education group means and standard deviations are calculated from the pooled data of seven waves of SCF survey $(1989,1992,1995$, 1998, 2001, 2004, 2007). CPI is used to adjust asset levels to 1998 dollar. 


\subsection{Weighting matrix}

In the basic model, we use the inverse of the variances of the moments as the weighting matrix. This is a diagonal matrix. The usual variance-covariance matrix is not used for two reasons. First, the moments are from two data sets: PSID and SCF, so it is not possible to calculate covariances of moments from different sources. Second, stock shares from SCF are based on a small sample containing only stockholders, while participation rates and wealthincome ratios are based on a larger sample including non-participants. Therefore one can only have covariances of moments for stockholders only, weighting matrix from which may not be more informative than diagonal matrix for our estimation.

Table 15: Weights on Data Moments

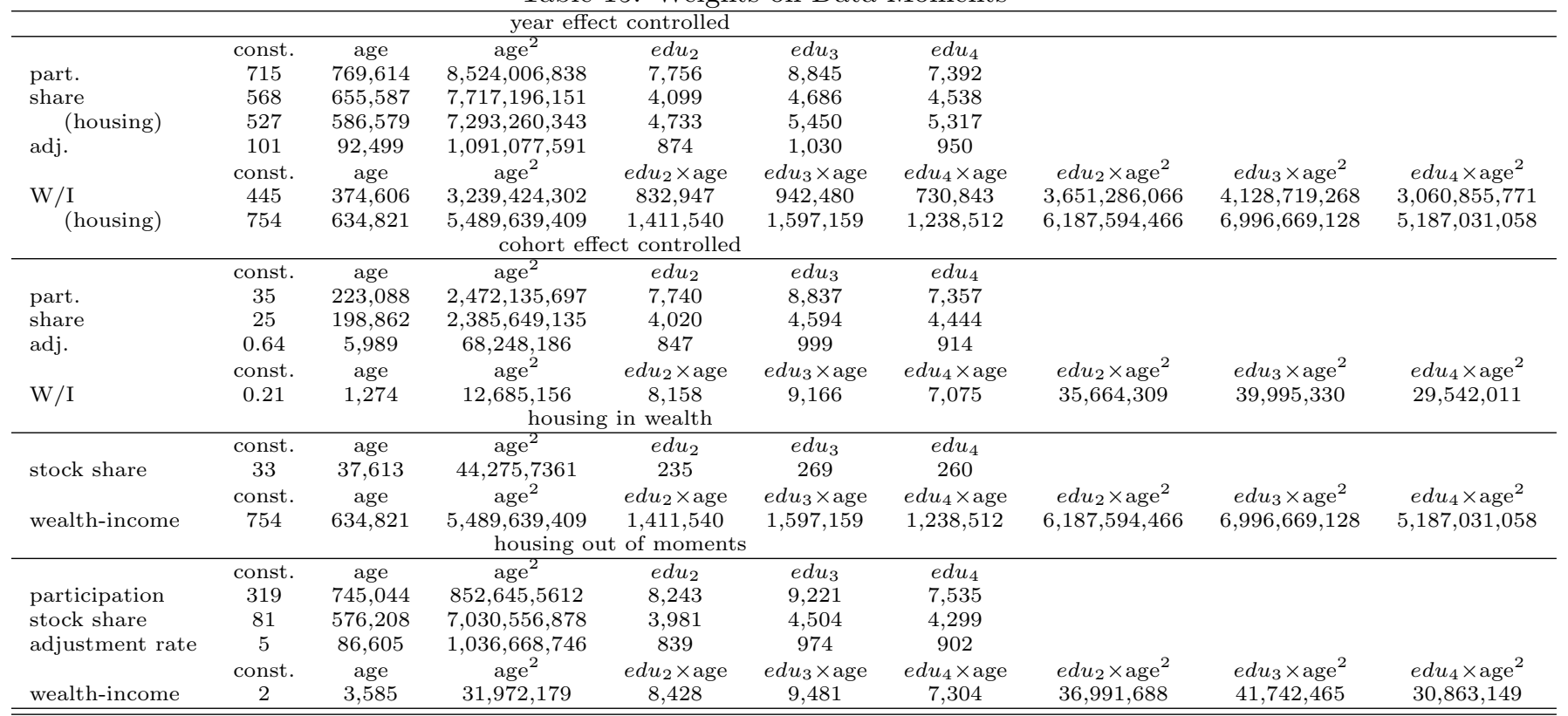

This table reports the weights used to compute model fits in the Simulated Method of Moments. The weights are calculated as the inverse of the variances of data moments. 


\subsection{Moments From Heterogeneous Preferences Models}

Table 16: Heterogeneous Preferences Models: Moments

\begin{tabular}{|c|c|c|c|c|c|c|c|c|c|}
\hline & const. & age & age $^{2}$ & $e d u_{2}$ & $e d u_{3}$ & $e d u_{4}$ & & & \\
\hline \multicolumn{10}{|c|}{ Participation } \\
\hline data & -0.680 & 0.029 & -0.00023 & 0.182 & 0.412 & 0.603 & & & \\
\hline hetero $\beta$ & -0.658 & 0.029 & -0.00022 & 0.183 & 0.433 & 0.567 & & & \\
\hline hetero $\gamma$ & -0.610 & 0.031 & -0.00025 & 0.196 & 0.400 & 0.519 & & & \\
\hline hetero $\Gamma$ & -0.634 & 0.029 & -0.00023 & 0.170 & 0.421 & 0.558 & & & \\
\hline hetero $F$ & -0.670 & 0.032 & -0.00026 & 0.205 & 0.407 & 0.530 & & & \\
\hline hetero $\theta$ & -0.615 & 0.031 & -0.00025 & 0.190 & 0.420 & 0.530 & & & \\
\hline \multicolumn{10}{|c|}{ Stock Share } \\
\hline data & 0.260 & 0.010 & -0.00008 & 0.024 & 0.054 & 0.092 & & & \\
\hline hetero $\beta$ & 0.402 & 0.013 & -0.00011 & 0.044 & 0.059 & 0.081 & & & \\
\hline hetero $\gamma$ & 0.394 & 0.014 & -0.00012 & 0.023 & 0.051 & 0.058 & & & \\
\hline hetero $\Gamma$ & 0.364 & 0.014 & -0.00010 & 0.052 & 0.069 & 0.097 & & & \\
\hline hetero $F$ & 0.416 & 0.014 & -0.00012 & 0.031 & 0.045 & 0.077 & & & \\
\hline hetero $\theta$ & 0.394 & 0.013 & -0.00011 & 0.037 & 0.054 & 0.070 & & & \\
\hline \multicolumn{10}{|c|}{ Adjustment Rate } \\
\hline data & 0.189 & 0.012 & $-0.000 \overline{13}$ & 0.061 & 0.135 & 0.222 & & & \\
\hline hetero $\beta$ & -0.251 & 0.009 & -0.00006 & 0.035 & 0.158 & 0.252 & & & \\
\hline hetero $\gamma$ & -0.342 & 0.015 & -0.00010 & 0.050 & 0.156 & 0.233 & & & \\
\hline hetero $\Gamma$ & -0.199 & 0.007 & -0.00003 & 0.045 & 0.120 & 0.195 & & & \\
\hline hetero $F$ & -0.279 & 0.013 & -0.00008 & 0.038 & 0.132 & 0.290 & & & \\
\hline hetero $\theta$ & -0.240 & 0.009 & -0.00005 & 0.059 & 0.164 & 0.241 & & & \\
\hline \multicolumn{10}{|c|}{ wealth-income Ratio } \\
\hline & const. & age & $\operatorname{age}^{2}$ & $e d u_{2} \times$ age & $e d u_{3} \times$ age & $e d u_{4} \times$ age & $e d u_{2} \times \operatorname{age}^{2}$ & $e d u_{3} \times \operatorname{age}^{2}$ & $e d u_{4} \times \operatorname{age}^{2}$ \\
\hline data & 1.393 & -0.086 & 0.00132 & -0.012 & -0.015 & -0.004 & 0.00051 & 0.00114 & 0.00130 \\
\hline hetero $\beta$ & 1.106 & -0.042 & 0.00052 & -0.003 & -0.024 & -0.059 & 0.00013 & 0.00069 & 0.00167 \\
\hline hetero $\gamma$ & 1.478 & -0.060 & 0.00071 & 0.001 & -0.018 & -0.046 & 0.00008 & 0.00056 & 0.00136 \\
\hline hetero $\Gamma$ & 1.905 & -0.078 & 0.00088 & 0.000 & -0.020 & -0.057 & 0.00010 & 0.00062 & 0.00155 \\
\hline hetero $F$ & 1.037 & -0.043 & 0.00059 & -0.002 & -0.021 & -0.049 & 0.00016 & 0.00068 & 0.00146 \\
\hline hetero $\theta$ & 1.676 & -0.061 & 0.00065 & -0.005 & -0.032 & -0.071 & 0.00022 & 0.00092 & 0.00192 \\
\hline
\end{tabular}

These are the coefficient estimates from various heterogeneous preferences models. With the exception of the wealth-income equation, these come from a linear regression model with a constant, age, age-squared, and education dummies as independent variables. For the wealth-income regressions, the independent variables were a constant, age, age-squared and an education dummies interacted with age and age-squared. 


\section{References}

Achury, C., S. Hubar, and C. Koulovatianos (2012): "Saving rates and portfolio choice with subsistence consumption," Review of Economic Dynamics, 15(1), 108-126.

Alan, S. (2006): "Entry Costs and Stock Market Participation over the life cycle," Review of Economic Dynamics, $9,588-611$.

Ameriks, J., And S. P. Zeldes (2004): "How do household portfolio shares vary with age," Discussion paper, working paper, Columbia University.

Aoki, K., A. Michaelides, and K. Nikolov (2012): "Inflation, Money Demand and Portfolio Choice," mimeo, ECB.

Attanasio, O. P., and M. Paiella (2011): "Intertemporal Consumption Choices, Transaction Costs and Limited Participation in Financial Markets: Reconciling Data and Theory," Journal of Applied Econometrics, 26(2), $322 \mathrm{C} 343$.

Bhamra, H. S., and R. Uppal (2006): "The role of risk aversion and intertemporal substitution in dynamic consumption-portfolio choice with recursive utility," Journal of Economic Dynamics and Control, 30(6), 967991.

Binsbergen, J., J. Fernandez-Villaverde, R. Koijen, and J. Ramirez (2012): "The terms tructure of interest rates in a DSGE model with recursive preferences," Journal of Monetary Economics, 59(7), 634-648.

Bodie, Z., R. C. Merton, and W. F. Samuelson (1992): "Labor supply flexibility and portfolio choice in a life-cycle model," Journal of Economic Dynamics and Control, 16(3-4), 427-449.

Bonaparte, Y., R. Cooper, and G. Zhu (2012): "Consumption Smoothing and Portfolio Rebalancing: The Effects of Adjustment Costs," Journal of Monetary Economics, 59, 751-68.

Cagetti, M. (2003): "Wealth accumulation over the life cycle and precautionary savings," Journal of Business 83 Economic Statistics, 21(3), 339-353.

Calvet, L. E., J. Y. Campbell, and P. Sodini (2007): "Down or Out: Assessing the Welfare Costs of Household Investment Mistakes," Journal of Political Economy, 115(5), 707-747.

_ (2009): "Fight or flight? Portfolio rebalancing by individual investors," The Quarterly journal of economics, 124(1), 301-348.

Campbell, J. Y. (2006): "Household finance," The Journal of Finance, 61(4), 1553-1604.

Campbell, S. D., M. A. Davis, J. Gallin, and R. F. Martin (2009): "What moves housing markets: A variance decomposition of the rent-price ratio," Journal of Urban Economics, 66(2), 90-102. 
Carroll, C., and A. A. Samwick (1997): "The nature of precautionary wealth," Journal of Monetary Economics, 40(1), 41-71.

Cocco, J. F. (2005): "Portfolio choice in the presence of housing," Review of Financial studies, 18(2), 535-567.

Cocco, J. F., F. J. Gomes, and P. J. Maenhout (2005): "Consumption and portfolio choice over the life cycle," Review of financial Studies, 18(2), 491-533.

Cole, S., A. Paulson, and G. K. Shastry (2014): "Smart Money: The Effect of Education on Financial Outcomes," Review of Financial Studies, 27(7), 2022-2051.

Cooper, R., And G. Zhu (2013): "Household finance: Education, permanent income and portfolio choice," NBER Working Paper \#13824.

DeNardi, M., E. French, And J. B. Jones (2006): "Differential mortality, uncertain medical expenses, and the saving of elderly singles," Working Paper 12554, National Bureau of Economic Research.

(2010): "Why Do the Elderly Save? The Role of Medical Expenses," Journal of Political Economy, 118(1), $39-75$.

Dynan, K., J. Skinner, and S. Zeldes (2004): "Do the rich save more?," Journal of Political Economy, 112(2), 397-444.

EPStein, L., AND S. Zin (1989): "Substitution, risk aversion, and the temporal behavior of consumption and asset returns: A theoretical framework," Econometrica: Journal of the Econometric Society, pp. 937-969.

French, E., And J. B. Jones (2004): "On the distribution and dynamics of health care costs," Journal of Applied Econometrics, 19(6), 705-721.

Gomes, F., and A. Michaelides (2005): "Optimal life-cycle asset allocation: understanding the empirical evidence," Journal of Finance, 60(2), 869-904.

- (2008): "Asset Pricing with Limited Risk Sharing and Heterogeneous Agents," Review of Financial Studies, $21(1), 415-448$.

Gomes, F. J., L. J. Kotlikoff, And L. M. Viceira (2008): "Optimal Life-Cycle Investing with Flexible Labor Supply: A Welfare Analysis of Life-Cycle Funds," American Economic Review, 98(2), 297-303.

Guvenen, F. (2009): “An Empirical Investigation of Labor Income Process," Review of Economic Dynamics, 12, $58-79$.

Haliassos, M., and A. Michaelides (2003): "Portfolio choice and liquidity constraints," International Economic Review, 44, 143-177. 
Heaton, J., And D. LuCAS (1997): "Market frictions, savings behavior, and portfolio choice," Macroeconomic Dynamics, 1(1), 76-101.

Hubbard, R., J. Skinner, and S. Zeldes (1994): "The importance of precautionary motives in explaining individual and aggregate saving," in Carnegie-Rochester Conference Series on Public Policy, vol. 40, pp. 59-125. Elsevier.

(1995): "Precautionary Saving and Social Insurance," Journal of Political Economy, 103(2), 360-399.

Keane, M. P., and K. I. Wolpin (2001): "The effect of parental transfers and borrowing constraints on educational attainment," International Economic Review, 42(4), 1051-1103.

Lleras-Muney, A. (2005): "The relationship between education and adult mortality in the United States," The Review of Economic Studies, 72(1), 189-221.

Lusardi, A. (2008): "U.S. Household Savings Behavior: The Role of Financial Literacy, Information and Financial Education Programs," NBER Working Paper \#13824.

Merton, R. C. (1971): "Optimum consumption and portfolio rules in a continuous-time model," Journal of Economic Theory, 118(3), 373C413.

Starr-McCluer, M. (1996): "Health insurance and precautionary savings," The American Economic Review, 86(1), 285-295.

Vissing-Jorgensen, A. (2002a): "Limited Asset Market Participation and the Elasticity of Intertemporal Substitution," Journal of Political Economy, 110(4), 825-853.

Vissing-Jorgensen, A. (2002b): "Towards an explanation of household portfolio choice heterogeneity: Nonfinancial income and participation cost structures," NBER Working Paper \#8884.

Vissing-Jorgensen, A., and O. P. Attanasio (2003): "Stock-Market Participation, Intertemporal Substitution, and Risk-Aversion," American Economic Review, Papers and Proceedings, 93(2), 383-391.

Wachter, J. A., and M. Yogo (2010): "Why Do Household Portfolio Shares Rise in Wealth?," Review of Financial Studies, 23(11), 3929-3965.

WeIL, P. (1990): "Nonexpected utility in macroeconomics," The Quarterly Journal of Economics, 105(1), $29-42$.

YAO, R., And H. H. Zhang (2005): "Optimal consumption and portfolio choices with risky housing and borrowing constraints," Review of Financial Studies, 18(1), 197-239. 